\title{
The Premium as Informational Cue in Insurance Decision Making
}

\author{
Robin Chark* \\ Faculty of Business Administration, University of Macau, Macau, China \\ Vincent Mak \\ Cambridge Judge Business School, University of Cambridge, \\ Trumpington Street, Cambridge CB2 1AG, United Kingdom
}

\begin{abstract}
A.V. Muthukrishnan
Department of Marketing, The Hong Kong University of Science and Technology, Clear Water Bay, Hong Kong
\end{abstract}

July 6, 2019

* Corresponding author. E-mail: rchark@umac.mo, Tel: +853-8822-4136, Fax: +853-8822-2377 


\title{
The Premium as Informational Cue in Insurance Decision Making
}

\begin{abstract}
Often in insurance decision making, there are risk factors on which the insurer has an informational advantage over the consumer. But when the insurer sets and posts a premium for the consumer to consider, the consumer can potentially use the premium as an informational cue for the loss probability, and thereby to reduce the insurer's informational advantage. We study, by means of a behavioral model, how consumers would use the premium as an informational cue in such contexts. The belief formation process in our model assumes that both prior knowledge and the premium (as a proportion of the compensation) might have an impact on the consumer's estimate of the loss probability. Moreover, the premium impacts the estimate through an anchoring-and-adjustment process. The model potentially leads to violations of rational expectations, with which the consumer overestimates the loss probability beyond what could be inferred from the premium, given the premise that the insurer must seek to break even or earn an expected profit. Our model analysis moreover implies that the frequency of such violations is non-increasing as the premium increases. Lastly, the model implies a generally inverted-U relationship between insurance demand and the premium, so that the demand is upward sloping at low premium levels and downward sloping at high premium levels. A pilot field study and a laboratory experiment provide robust evidence for our model implications and calibrations for its parameters.
\end{abstract}

Keywords: insurance; anchoring and adjustment; rational expectations; behavioral economics; experiments

JEL: C90, D81, D82, D84, G22 


\section{Introduction}

When a consumer considers whether to purchase an insurance package, three major factors are typically at play: the premium; the compensation in the event of a loss, failure, or breakdown; and the likelihood of the loss occurring. Much of the voluminous research literature on insurance decision making views the consumer's decision problem as a tradeoff between the prospective sunk payment of the premium - a cost component - on one hand, and the potential compensation and loss probability on the other (see, e.g., Kunreuther et al. 2013, and the Related literature section).

However, there are also numerous examples in which the premium can have informational value to insurance purchase decisions, over and above its role as a cost component. These examples occur when the insurer has an informational advantage over the consumer regarding certain exogenous risk factors. Once the insurer sets and posts a premium for the consumer to consider, the consumer can potentially use the premium as an informational cue for the loss probability, and thereby to reduce the insurer's informational advantage. To be more specific, consider a firm offering an insurance package to cover predominantly exogenous risks over which the firm has much more information than the consumers. For example, the package might provide compensation in the event of the loss of a parcel during delivery, the cancellation of a scheduled flight, the cancellation of a tour group due to bad weather, etc. Suppose the insurer makes a take-it-or-leave-it, stand-alone offer with fixed compensation, in exchange for an upfront premium payment. Could the consumer make any inference from the premium that could provide value to his/her insurance purchase decision?

Normatively, the answer to this question is affirmative. First, the consumer should be able to appreciate that the insurer has an informational advantage over the loss probability. Moreover, 
the consumer might expect that the insurer could only be risk neutral or risk averse regarding the offer. That is, the insurer could not be offering a package that would expose itself to an expected loss; or equivalently, the insurer must be offering a package that allows it to break even or earn a profit over the expected loss to be covered. If the consumer factors in such considerations upon observing the offer, he/she would arrive at a new upper bound of the loss probability, namely the premium as a proportion of the compensation. This realization, which abides by rational expectations, would influence the consumer's insurance purchase decision. As an illustrative (and anecdotal) example, the authors know of a consumer who decided not to purchase insurance for his piano when moving house, precisely because the offered premium was "too low". The consumer's intuition was that, given the premium, the loss probability could not be high enough for the insurance to be worth purchasing.

Behaviorally, where a consumer is influenced by the premium (vis-à-vis the compensation) during the estimation of the loss probability, the actual estimation process might be largely heuristic. A likely candidate of such heuristics is anchoring-and-adjustment from the premium; a closely related example, to be explored further below, is Einhorn and Hogarth (1985)'s probabilistic inference model (see also Hogarth and Kunreuther 1989). Moreover, consumers typically have some prior knowledge about the loss probability, and this prior knowledge as well as the premium would impact the consumer's estimate of the loss probability, possibly in an asymmetric fashion. The dual impact of prior knowledge and premium, coupled with the use of heuristics, could lead to various behavioral regularities. For instance, it might not always result in beliefs that are consistent with rational expectations. As Rabin and Thaler (2001, p.225) point out, in general, consumers' insurance purchase decisions might violate rational expectations assumptions. In short, in insurance decision making, the premium might have some impact as an 
informational cue, but the consumer's use of it might not abide by standard economic rationality.

In this article, we attempt to capture the above ideas by means of a descriptive, behavioral model of the premium as an informational cue in insurance decision making. In line with our research objective, our model (as well as the experiment that tested its implications) focuses on a simplified situation in which the insurer has private information about the loss probability while the consumer has no private information. The belief formation process in our model further assumes that both prior knowledge and the premium - standardized as a proportion of the compensation - might have an impact on the consumer's estimate of the loss probability. Moreover, the premium impacts the estimate through an anchoring-and-adjustment process. The model potentially leads to violations of rational expectations, with which the consumer overestimates the loss probability beyond what could be inferred from the premium, given the premise that the insurer must seek to break even or earn an expected profit. Our model analysis implies that the frequency of such violations is non-increasing as the premium increases. Furthermore, the model implies a generally inverted- $U$ relationship between insurance demand and the premium, so that the demand is upward sloping at low premium levels and downward sloping at high premium levels.

To obtain further empirical evidence for our model, we next conducted a pilot field study and a laboratory experiment. Our findings provide consistent support for the model implications, and also provide calibrations for its parameters. In sum, our results suggest that, when consumers form beliefs over the loss probability, they take into account the offered premium to some extent, but often insufficiently so.

\subsection{Related literature}

Our emphasis on the premium's informational value is of crucial importance in a normative as 
well as descriptive sense, because: (1) it is a piece of credible information that the insurer must communicate to the consumer as an essential component of the package; and (2) it can potentially narrow down the knowledge gap between insurer and consumer regarding the loss probability. However, this potential value of the premium has been rarely investigated in the insurance decision making literature. The literature is traditionally concerned with testing the hypothesis of expected utility maximization when the loss probability is given (e.g., Cutler and Zeckhauser 2004; Kunreuther et al. 2013; Jindal 2015). Those investigations typically have a focus on applying prospect theory (Kahneman and Tversky 1979) and relatedly, reference dependence and loss aversion (Köszegi and Rabin 2006; Sydnor 2010) as well as the overweighting of small probabilities (Barseghyan et al. 2013; see also Tversky and Fox 1995 and Tversky and Wakker 1995); see Ho et al. (2006) for some further discussion and Jindal (2015) for recent development. There is a similar emphasis in a more general stream of literature on decision behavior; in that literature, the decision maker's estimates of the probabilities of observing different outcomes are usually taken as given, and the focus is on how the estimated probabilities are combined or are translated into decision weights (e.g., Abdellaoui et al. 2011; Kilka and Weber 2001; Tversky and Fox 1995; Tversky and Wakker 1995).

Meanwhile, a long theoretical and empirical literature in insurance economics, starting from Rothschild and Stiglitz (1976) and Stiglitz (1977) with recent development including Chade and Schlee (2012), Hendren (2013), and Koufopoulos and Kozhan (2014), looks at asymmetric information between insurers and consumers. However, the focus in those studies is typically on cases where the consumer has an informational advantage over the insurer regarding his/her own risk characteristics, which is a different class of problems from the one studied here. In those cases, the premium is the insurer's decision variable upon considering the adverse selection 
problems from more informed consumers; while here we study how the premium might be treated as a signal by consumers who are less informed than the insurer regarding an exogenous loss probability.

Our study connects with two other streams of literature. The first includes research that examines how people form probability estimates and the moderating influence of qualitative contextual factors in an anchoring-and-adjustment context (e.g., Epley 2004; Epley and Gilovich 2010). By contrast, our examination is on how consumers' belief of loss probability might be a function of a ratio-scale quantity, namely the offered premium as a proportion of the compensation, which is an essential element of the decision situation rather than a contextual factor. There are few studies in the literature on probability estimates with a similar aim. One exception is Einhorn and Hogarth (1985)'s quantitative model of probabilistic inference, which motivates part of the belief formation process in our model.

Another stream of relevant literature is that on cursedness of players in games with asymmetric information, in the sense defined by Eyster and Rabin (2005). According to Eyster and Rabin, cursed players are those who underappreciate the informational content of other players' actions. Examples of experimental studies on cursedness include the "winner's curse" in common value auctions (Kagel and Levin 1986) and behavior in Acquiring-a-Company or similar bilateral trade experiments with adverse selection (Ball et al. 1991; Charness and Levin 2009; Holt and Sherman 1994). Notably, where these previous experiments identified instances of failure to form rational expectations, all of them were concerned with a riskless prospect with fixed value (though uncertain to the decision maker). Our experiment is thus among the first in identifying similar behavioral regularities with risky prospects, so that what is not known fully to the decision maker is the risk of the prospect, and there is unresolved uncertainty even after 
trade.

\section{The model}

\subsection{Basic setup and rational expectations}

Consider a monopolistic insurer, $I$, and a consumer, $C$, who are both expected utility maximizers. $I$ has an opportunity to make a take-it-or-leave-it, stand-alone offer with fixed, full-coverage compensation $c$ in the event of a predefined loss or breakdown event, in exchange for an upfront premium payment of $p c$. As such, $p$ is the standardized premium expressed as a proportion of the compensation; we shall often call $p$ the "premium" unless there is potential confusion.

Denote $C$ 's Bernoulli utility function as $U_{C}(\cdot)$. Without loss of generality and for expositional convenience, we adopt the normalization assumption that $U_{C}(0)=0$. The loss probability, $q$, was known to $I$ but not to $C$, who only holds a prior probability distribution of $q$ at the outset. This prior distribution is commonly known to both $I$ and $C$.

If $C$ accepts I's offer, $C$ 's (expected) utility is $U_{C}(-p c)$. If $C$ rejects $I$ 's offer, $C$ 's expected utility is $\mathrm{E}_{C}[q \mid p] \cdot U_{C}(-c)$, where $\mathrm{E}_{C}[q \mid p]$ is $C$ 's expected value of $q$ conditional on observing that $I$ has presented an offer with premium $p$. Thus, if there is a trade i.e., if $C$ accepts $I$ 's offer, we must have $U_{C}(-p c) \geq \mathrm{E}_{C}[q \mid p] \cdot U_{C}(-c)$ or:

$$
\mathrm{E}_{C}[q \mid p] \geq U_{C}(-p c) / U_{C}(-c)=q_{C}(p)
$$

$q_{C}(p)$ being a function of $p$ (note that both utility terms on the right-hand side are negative). The intuition of inequality (1) is that $C$ only purchases insurance when he/she expects the loss probability is sufficiently large given the premium and his/her risk attitude.

If $C$ is risk neutral, $p \equiv q_{c}(p)$. If $C$ is risk averse, it can be shown that: (a) $p=q_{c}(p)$ when $p=$ 0 and $p=1,(\mathrm{~b}) q_{c}(p)$ is a strictly convex and increasing function in $p$, and (c) $p>q_{c}(p)$ when $0<$ $p<1$. For example, property (c) can be deduced by observing that $U_{C}(\cdot)$ is concave so that, for 
any $p$ within $[0,1], U_{C}(-p c) \geq p U_{C}(-c)$. Division by $U_{C}(-c)$ on both sides (and reversing the inequality sign since $U_{C}(-c)$ is negative) then yields property (c). Fig. 1 shows an example of $q_{c}(p)$ in this case, and its position relative to the prior mean $\bar{q}$, which is the expected value of $q$ according to its prior distribution. The value of $\bar{q}$ in the figure is 0.25 , which is true when, for example, the prior is a uniform distribution over $0,0.01,0.02, \ldots 0.5$ as in the laboratory experiment in this study. The figure is plotted over $0 \leq p \leq 1$, the reasonable range of $p$. Acceptance of offer occurs whenever $\mathrm{E}_{C}[q \mid p]$ is on or above the $q_{c}(p)$ curve.

- Insert Fig. 1 around here -

2.1.1 Equilibrium analysis. In Appendix A, we describe an equilibrium analysis of this model under standard assumptions regarding common rationality, and the assumption that the Bernoulli utility functions of both insurer and consumer are common knowledge. Our main result (Proposition A1) is that if there are any trades at all, they should all occur at the same premium level. However, this is clearly refuted by our experimental data, in which trades typically occurred at multiple premium levels, and the same consumer subject often accepted offers at more than one premium levels. Even if we relax the common rationality assumption to follow treatments such as Eyster and Rabin (2005)'s cursed equilibrium model, the assumption of the Bernoulli utilities being common knowledge - empirically speaking a very strong assumption would still be needed for the analysis to be reasonably tractable.

Thus, from here onwards, we shall proceed with further analysis without requiring the assumption of the Bernoulli utilities being common knowledge. We next establish some general results regarding rational expectations.

2.1.2 The baseline rational expectations hypothesis (BREH). We adopt the following general assumptions regarding the consumer: (1) the consumer is risk averse; and (2) the 
consumer assumes that the insurer is either risk averse or risk neutral. Given assumption (1), assumption (2) is consistent with previous literature on people's perception of others' risk attitude, e.g., Hsee and Weber (1997) and Faro and Rottenstreich (2006), as well as previous findings on insurers' risk attitude (Hogarth and Kunreuther 1989). Therefore, if $C$ 's updated belief abides by rational expectations, that belief must place zero probability on true values of $q$ that would yield an expected loss to $I$, given the offered premium $p$. Since $I$ 's expected payoff from selling a package is $q(p c-c)+(1-q) p c=(p-q) c$, this means that $C$ 's updated belief must place zero probability on true values of $q$ that are greater than $p$. To put it more intuitively, a consumer who follows rational expectations would be aware that the insurer would ensure that its revenue (i.e., $p c$ ) would break even or make a profit over the expected loss to be covered (i.e., $q c)$. Thus $p$ cannot be less than $q$, and hence the following must be true with the consumer's updated belief: ${ }^{1}$

$$
p \geq \mathrm{E}_{C}[q \mid p]
$$

In words, we propose the following hypothesis:

\section{Baseline rational expectations hypothesis (BREH) The consumer's expected value of the loss} probability is not higher than the offered premium.

Violation of the BREH occurs whenever $\mathrm{E}_{C}[q \mid p]$ is above the diagonal (i.e., in the shaded

\footnotetext{
${ }^{1}$ An implicit assumption here is as follows: $I$ always expects that there is some positive probability that $C$ will accept his/her offer, whatever the premium (or, more rigorously, that $C$ believes that $I$ expects so). This is consistent with refinement ideas in the game theory literature, such as sequential equilibrium (Kreps and Wilson 1982), which assumes that players may tremble and thus there is always a positive probability for a player to play any available strategy, including out-of-equilibrium strategies (in which case the probability is infinitesimally small). On the other hand, if $C$ considers that $I$ may make "mistakes" in the form of a zero-mean random shock around what $I$ might have intended to offer under the aim of expected utility maximization, then at least the expected value of $q$ under $C$ 's belief should not be higher than $p$, and the inequality must still hold.
} 
area) in Fig. 1. This hypothesis is a necessary but not sufficient condition for consumer belief to satisfy rational expectations, and hence is described as a "baseline" hypothesis. For example, if a consumer does not update his/her belief conditional on observing the offered premium, his/her expected loss probability is always the prior mean $\bar{q}$; however, even such a consumer's belief will violate the BREH only when the offered premium is less than the prior mean.

Testable Implication 1: Purchase probability under violation of the BREH. We next relate violations of rational expectations to the consumer's purchase probability. In keeping with probabilistic choice models (e.g., Luce 1959; McFadden 1980), we assume that, empirically, the expected utility framework in the previous analysis only describes the deterministic component of the consumer's utility. In addition, the consumer's utility has a stochastic component that varies from decision to decision as an i.i.d. zero-mean random shock with symmetric distribution around the mean. Hence there is typically always some probability that the consumer accepts the offer whether $\mathrm{E}_{C}[q \mid p] \geq q_{c}(p)$ or not, but this probability strictly increases with the difference between the expected utilities of purchase and non-purchase, which means that it increases with $\mathrm{E}_{C}[q \mid p]-q_{c}(p)$. Therefore, controlling for $p$, a consumer is more likely to make a purchase when he/she has violated the BREH (i.e., when $\mathrm{E}_{C}[q \mid p]>p$ ), compared with otherwise (i.e., when $\left.\mathrm{E}_{C}[q \mid p] \leq p\right)$. Moreover, since the random shock is zero-mean and symmetrically distributed, whenever the deterministic component of the utility is positive, the probability of purchase must be larger than 0.5 . Thus, whenever a consumer violates the BREH, his/her purchase likelihood must be more than $50 \%$. As this is true for all consumers who violate the BREH, we propose the following to be tested on our experimental data:

Testable implication 1 Among consumers whose beliefs violate the BREH with respect to an 
offer, more than half purchase that offer.

\subsection{The belief formation process in the model and its implications}

We next model the belief formation process of the consumer under the setup established so far. We first recognize that, in general, both prior knowledge and the premium (in its standardized form, $p$ ) would have an impact on the consumer's estimate of the loss probability. Quantitatively, the impact of the prior knowledge can be represented by the prior mean, $\bar{q}$. Meanwhile, the impact of the premium can be represented by $E_{C}^{R}(q \mid p)$, the component of his/her belief that is consistent with the BREH. We can express $E_{C}^{R}(q \mid p)$ as $E_{C}^{R}(q \mid p)=p-f(p)$, where $f(p) \geq 0$ is a function of the premium. Observe that $f(p) \cdot c=p c-\left[E_{C}^{R}(q \mid p) \cdot c\right]$; thus the value of $f(p)$ can be interpreted as the consumer's rational expectations estimate of the insurer's target profit (as a proportion of the compensation) over the expected loss to be covered.

For the sake of simplicity and parsimony, we next assume a linear formulation of the dual impact of prior knowledge and the premium on the consumer's estimate of the loss probability. That is, we assume that the consumer's estimate of the loss probability is a weighted average of the prior estimate of the loss probability and the estimate conditional on observing the premium, with weights $\alpha$ and 1- $\alpha$ respectively, where $0 \leq \alpha \leq 1$. Therefore, the consumer's updated expected value of $q$ is:

$$
\begin{gathered}
E_{C}[q \mid p]=\alpha \bar{q}+(1-\alpha) E_{C}^{R}[q \mid p] \\
=\alpha \bar{q}+(1-\alpha)[p-f(p)] \\
=[\alpha \bar{q}+(1-\alpha) p]-(1-\alpha) f(p) .
\end{gathered}
$$

The case $\alpha=0$ corresponds to a consumer whose updated belief always satisfies the BREH whatever the premium. The case $\alpha=1$ corresponds to a consumer who never updates his/her belief from the prior upon observing the premium. It is also helpful to consider the special case 
of $f(p) \equiv 0$ as an illustrative example, when $E_{C}[q \mid p]$ is simply the function $\alpha \bar{q}+(1-\alpha) p$. Fig. 1 presents how $\alpha \bar{q}+(1-\alpha) p$ changes with $p$ when $\alpha=1 / 4$.

To generate specific testable implications, we make the additional assumption that, in the component of the belief that follows the BREH, the downward adjustment from the premium must be strictly increasing in $p$. That is:

$$
f^{\prime}(p)>0
$$

This assumption is consistent with, for example, Einhorn and Hogarth (1985)'s empirically supported anchoring-and-adjustment model of probabilistic inference. A general premise of their model is that, given an anchor $p$, the consumer's downward adjustment tendency is a decreasing function in the probability above $p$ (i.e., $1-p$ ) and an increasing function in the probability below $p$ (i.e., $p$ ). This implies that, as $p$ increases (while $1-p$ decreases at the same time), the consumers must have a stronger tendency to adjust downward. Also, following the interpretation of $f(p)$ as noted earlier, this assumption implies that the consumer's estimate of the insurer's target profit (as a proportion of the compensation) is increasing in the premium level.

Lastly, we assume that the consumer's actual belief has a stochastic component that is an i.i.d. zero-mean random shock with symmetric distribution around the deterministic component modelled here.

Given the above, the difference between $E_{C}[q \mid p]$ and the premium, namely $E_{C}[q \mid p]-p=$ $\alpha(\bar{q}-p)-(1-\alpha) f(p)$, is strictly decreasing in $p$. Allowing for the random shock, there can still be observations of violations of the BREH even if this systematic difference is positive. However, since $E_{C}(q \mid p)-p$ remains strictly decreasing in $p$, the frequency of violations of the $\mathrm{BREH}$ in the population must be non-increasing at an aggregate level as the premium increases. Hence: 
Testable implication 2 The frequency of violations of the BREH is non-increasing as the premium increases.

Fig.1 offers a graphical intuition of this testable implication. When $p<\bar{q}$, the function $\alpha \bar{q}+$ $(1-\alpha) p$ is above the diagonal and increases less quickly with $p$ than the diagonal. At the same time, the adjustment function $f(p)$ also increases as the premium increases. Therefore, if $E_{C}[q \mid p]$ is higher than $p$ at small values of $p$, it should become closer to $p$ as $p$ increases, and might become less than $p$ and continues to be so as $p$ further increases beyond some critical value, say $p_{1}$ This means that, in general, the consumer might violate the BREH at small values of $p$ but satisfy the BREH at sufficiently high values of $p$. Moreover, for a sufficiently diffuse spread of $p_{1}$ among the consumers, the frequency of violations would be strictly decreasing in the premium over a wide range of premium.

In fact, since $E_{C}[q \mid p]-p=\alpha(\bar{q}-p)-(1-\alpha) f(p)<0$ when $p>\bar{q}$, the consumer's updated belief must follow the BREH when the premium exceeds the prior mean, according to our model. Allowing for the stochastic belief component that may lead to observations of violations even when $p>\bar{q}$, we present this result in the following form as a subsidiary testable implication:

Testable implication 2a The frequency of violations of the BREH with respect to an offer with premium $p$ is at least as high when $p<\bar{q}$, compared with when $p>\bar{q}$.

Our final testable implication is related to how demand for insurance might vary with the 
premium. Recall that the likelihood of purchase is strictly increasing in $E_{C}[q \mid p]-q_{C}(p)$, which is equal to:

$$
\alpha \bar{q}+(1-\alpha) p-(1-\alpha) f(p)-q_{C}(p)
$$

Now,

$$
\frac{\partial}{\partial p}\left[\alpha \bar{q}+(1-\alpha) p-(1-\alpha) f(p)-q_{C}(p)\right]=(1-\alpha)\left[1-f^{\prime}(p)\right]-q_{C}^{\prime}(p) .
$$

Hence, if $(1-\alpha)\left[1-f^{\prime}(0)\right]>q_{C}^{\prime}(0)$, the probability of purchase is strictly increasing in the offered premium at sufficiently low premium levels; in other words, the consumer's (probabilistic) demand for insurance will be upward sloping at those premium levels, leading to an inverted-U-shaped demand curve. Since $f^{\prime}(0)>0$ by our assumption, the premise holds only if $1-\alpha>q_{C}{ }^{\prime}(0)$. That is, the impact of the premium on belief is sufficiently large in the sense that the function $\alpha \bar{q}+(1-\alpha)$ pincreases more quickly with the premium than $q_{C}(\cdot)$ at low premium levels. In addition, the downward adjustment $f(p)$, which increases as the premium increases, must also increase at a sufficiently low rate with the premium at low premium levels for the result to hold. That is, for the component of the consumer's belief that follows the BREH, the consumer's adjustment from $p$ must not be too sensitive with the premium, at least when the premium is low.

Next, recall the properties of $q_{C}(\cdot)$ as illustrated in Fig. 1, which indicates that $q_{C}^{\prime}(1)>1>$ $\alpha$. Hence the purchase probability must be generally decreasing in the premium at high premium levels. If it is indeed true that $(1-\alpha)\left[1-f^{\prime}(0)\right]>q_{C}^{\prime}(0)$ with a sufficiently large proportion of consumers, the following possibility would be observed regarding the total demand:

Testable implication 3 The demand for insurance increases with the premium at sufficiently low premium levels and decreases with the premium at sufficiently high premium levels. 
A test of Testable Implication 3 on experimental data is especially worthwhile because a necessary condition for its occurrence is $1-\alpha>q_{C}{ }^{\prime}(0)>0$. That is, observation of Testable Implication 3 will suggest that consumers take into account the premium to some degree when forming their beliefs, despite possibly violating the BREH at the same time. In more detail, the intuition behind is that consumers in our model are affected in two ways by the premium level: the premium's role as an informational cue, and its role as a cost component. As an informational cue, a higher (lower) premium suggests a higher (lower) loss probability, which then has a positive (negative) impact on purchase inclination. On the other hand, as a cost component, a higher (lower) premium has a negative (positive) impact on purchase inclination. That is, these two impacts have opposite directional dependences on the premium level. Our analysis suggests that the opposite directional dependences could result in a positive sloping demand at low premium levels (when the informational cue effect dominates) and a negative sloping demand at high premium levels (when the cost effect dominates). The upshot is the possibility of an inverted-U dependence of demand on premium.

\section{Pilot field study}

In this section, we report a pilot field study to illustrate the violations of rational expectations that are implied by our model. The study included a short survey with students at a university in Singapore who purchased notebook computers at a discount through a notebook ownership scheme. When students picked up computers purchased through the scheme, they were approached by an established local insurance company providing third-party coverage to their computers against accidents, damage, theft/robbery, and misplacement, for one to three years. 
The insurance package involved replacing lost/damaged computer by the same or a closely similar model.

\subsection{Design}

We administered a short survey to 40 of the students who had purchased notebook computers through the notebook ownership scheme. We approached these students at the point when they picked up their computers and were offered the insurance package, but had not yet decided on whether to purchase the insurance or not. Specifically, subjects were first asked which notebook computers they had bought and were then presented with three pieces of information: (1) the average price in 2010 (the year before the study took place) of a one-year coverage package offered by the insurer, which was $\mathrm{S} \$ 50$ (US\$1 $\approx \mathrm{S} \$ 1.25)$, (2) the number of claims for that insurance package in 2010, which was 408, and (3) the average compensation per claim in 2010, which was $\$ \$ 1,112$. We obtained these figures by adopting information found in marketing materials provided by the third-party insurer. The surveyed subjects were then asked to provide their estimates of the number of insurance purchases in 2010.

If the insurer did not suffer from a loss, we should have:

$$
\begin{gathered}
\text { Total compensation } \leq \text { Total revenue, or } \\
\text { Number of claims } \times \text { Average compensation per claim } \\
\leq \text { Number of purchases } \times \text { Average package price. }
\end{gathered}
$$

Since the overall loss probability would be the number of claims divided by the number of purchases, the above inequality can be rewritten as:

Overall loss probability $\leq$ Average package price / Average compensation per claim, which is in fact a version of the BREH.

After substituting the relevant figures in the right hand side of the inequality, we deduce that 
the overall loss probability cannot be larger than $4.5 \%$. In other words, given the total number of claims of 408 , the total number of purchases should not be less than 9,074 . That is, if subjects followed the BREH and accepted the premise that the insurer (an established and experienced player in the market) would not offer packages that would incur overall losses to itself, the estimates should not be less than 9,074.

Our design avoided directly eliciting a probability estimate, but instead framed a probability estimation task with a frequentist presentation (Tversky and Kahneman 1983), through which the task became conceptually simpler. The subjects were given unlimited time to come up with their responses and allowed access to paper, stationery, as well as electronic calculating devices.

\subsection{Results}

Thirty-six out of the 40 surveyed subjects (i.e., a proportion of $90 \%$ ) gave estimates of the number of insurance purchases that were less than the BREH threshold of 9,074, the sales that the insurer would have to make in order to breakeven. In fact, the mean estimate was 5,310 (s.d. $=2,700)$, which was significantly less than 9,074 $(t=8.82, p<0.001)$, and corresponded to an overall loss probability of 408/5,310 $=7.7 \%$, which was far higher than our deduced upper bound of $4.5 \%$. The average estimated total annual revenue collected from the premiums was $\mathrm{S} \$ 50 \times 5,310=\mathrm{S} \$ 265,500 ;$ however, the total amount of compensation paid was $\mathrm{S} \$ 1,112 \times 408$

$=\mathrm{S} \$ 453,696$. If the subjects' estimates were correct on average, the third-party insurer must have been making a loss at the order of S\$188,196 (approximately US\$150,557) from the sales of insurance in the year 2010, amounting to a $71 \%$ loss margin.

\subsection{Discussion}

The subjects in our field study often failed to provide estimates that were consistent with the reasoning that the insurance packages must be sufficiently profitable to be offered at all. It might 
be contended that our rational expectations argument might not hold if other external environment factors such as competition were factored in. A major possibility is that the insurance package might be a loss leader which the insurer intentionally launched to attract consumers' attention, to lure its competitors' customers, and to increase its customer base for cross-selling purposes (nevertheless, informal verbal discussions with the subjects suggested that they did not consider the insurance packages to be loss leaders). To obtain more conclusive evidence regarding deviations from the BREH as well as the Testable Implications from our modelling analysis, we conducted a controlled laboratory experiment which we report in the next section.

\section{$4 \quad$ The experiment}

While our pilot field study offers preliminary evidence of an implication of our model, our laboratory experiment was designed to test the model implications comprehensively and with rigor. Hence, in the experiment, we simulated the simple insurance trading environment of our model in an incentivized context. An essential feature of our design was a reliable measurement of subject's beliefs of the loss probability upon observing an offered insurance premium. As such, we implemented three elicitation methods in between-subject conditions to make sure that any observed behavioral regularity was robust across different elicitation methods. The simplest incentive scheme that has been used to measure subjective beliefs is "all-or-nothing" (AON; e.g., Charness and Dufwenberg 2006; Dufwenberg et al. 2011). In our experiment, under AON, the subject received a positive reward for a precisely correct estimate of the loss probability, and zero otherwise. Two other common incentive schemes are the linear scoring rule (LSR; see Andersen et al. 2014) and the quadratic scoring rule (QSR; e.g., Nyarko and Schotter 2002), 
which we also employed in the experiment (see Section 4.1.1 for more details).

In addition, the belief elicitation task might be affected by the fact that the subjects also needed to make a purchase decision at the same time. It is, for example, plausible that a subject who had decided to commit a payment to purchase an insurance package might be more highly motivated by the loss probability belief elicitation incentives, because of a wealth effect. As such, different purchase decisions might lead to different degrees of motivations in the belief elicitation task. We conjectured that the impact, if there was any, could not be very significant, as we had tried to make incentivization of the belief elicitation sufficiently strong by design. To allow for further examination of this issue, we implemented an additional "spectator" treatment condition in which players were asked to provide beliefs without participating in any insurance trading game (cf. Offerman et al. 1996 for a similar treatment in a different context). The "spectator" treatment condition could inform us about whether the purchase decision task could affect performances in the belief elicitation task. Because of our particular research objective with respect to the "spectator" treatment, we implemented such a treatment under AON only, the findings of which we then compared with the AON condition with purchase decisions.

\subsection{Design}

One hundred twenty-nine undergraduates at a university in Hong Kong participated in four between-subject conditions, each condition consisting of one experimental session. In Conditions PLAY-AON ( $n=31)$, PLAY-LSR ( $n=34)$, and PLAY-QSR $(n=32)$, the subjects played an insurance trading game to be described below, with consumers' beliefs elicited using AON, LSR, and QSR respectively. In Condition SPEC-AON $(n=32)$, subjects were put in the role of spectators and asked to estimate the loss probability (under AON) upon observing the premiums set by previous insurer subjects in the PLAY-AON session. 
We first describe the procedures in the PLAY conditions. In the beginning of the session, all subjects were told that they would receive a $\$ 70$ show-up fee regardless of subsequent outcomes (all payments in the experiment were in Hong Kong dollar, US\$1 $\approx$ HK\$7.8). They then read the following scenario adapted from Moore and Eckel (2003) (sample instructions for the experiment are given in Appendix B):

Imagine you have a car. The car may suffer from some type of mechanical failure or breakdown and need to be repaired. You will choose between 1) taking a chance on the car breaking down and paying for a repair, which cost \$100, and 2) purchasing insurance to insure yourself against having to pay for a repair. However, you do not know the exact probability of the breakdown. You only know the probability ranges from $0-50 \%$. If you choose to purchase the insurance, you will pay the premium and keep the rest of your money. The risk is then transferred to the insurer.

Note that the compensation was set at $\$ 100$, so that subjects could straightforwardly work out the offered premium as a proportion of the compensation (i.e., the quantity $p$ in the model). The subjects next read:

At the beginning of the experiment, one of you will be chosen randomly as the insurer. We have to determine the exact percentage chance out of the $0-50 \%$ range. Each of the percentage chances of the car needing a repair in the range is equally likely. The insurer will draw from a box a chip of 51 chips to determine the exact percentage chance of the car needing repair. (There are 51 numbers in the range of $0-50 \%: 0,1,2,3, \ldots, 49,50$.) Let's suppose the insurer draw a 9. Then the percentage chance of the car needing repair is $9 \%$. In other words, the prior distribution of the breakdown or loss probability was approximately a uniform distribution over $[0 \%, 50 \%]$ in our experiment. We adopt this in favor of other 
probability distributions, such as the normal distribution (Kubovy et al. 1971), for its ease of comprehension. The loss probability was only known to the insurer but not the consumer subjects until the end of the experiment. After the insurer learned of the probability, he/she set a premium that was announced to all other subjects, who were assigned the role of consumers (i.e., drivers in the experimental scenario) and were asked to make two decisions. First, they had to decide whether or not they would accept the insurer's offer and buy the insurance. Second, they were asked to estimate the exact percentage chance of breakdown that was drawn by the insurer. This concluded one round in the session, which consisted of a total of 10 rounds.

The loss probability in any round was not revealed to the consumers until all 10 rounds were over. By that time, 10 consumer subjects were randomly chosen to each play a separate round for money, using the decisions he/she made earlier regarding whether to accept the insurer's offer in that round and his/her estimate of the loss probability in that round. The chosen consumer for each round would be given an endowment of $\$ 100$ - from which the premium would be deducted if he/she accepted the insurance offer in that round - and then asked to resolve the residual uncertainty of the breakdown of the car in the following way:

[The chosen] driver will draw a chip from another box of 100 chips (1 - 100) to determine whether or not the car needs a repair. If the number is higher than the percentage chance, the car is fine. If the number the driver draws is equal to or smaller than the percentage chance of the car needing a repair, then the car has a breakdown. Following the above example where the drawn percentage chance is 9, if the driver draws a 10 or above, the car is fine. If the driver draws a 9 or smaller, the car breaks down. The cost of the repair is borne by either the driver or the insurer depending on the driver's insurance decisions as discussed above. The cost of the repair simply goes back to the experimenter's research fund. 
Finally, the insurer was paid the total of an endowment of $\$ 200$ plus the earnings (which could be a gain in addition to, or a loss to be deducted from, the endowment) he/she received from the outcomes of two randomly chosen rounds.

In the SPEC-AON condition, subjects were only spectators and did not play the insurance trading game. At the beginning of their session, they were told that they would receive a show-up fee of $\$ 50$ and then introduced to the experimental setup of the PLAY conditions. Afterwards, they were given the premiums set by the insurer subject in the 10 rounds of the PLAY-AON condition. Finally, they were asked to make an estimate of the realized loss probabilities in all 10 rounds and were paid according to whether they estimated the probabilities correctly, to be described below.

4.1.1 Belief elicitation procedures. The consumer subjects in the PLAY conditions and all subjects in the SPEC-AON conditions could obtain payments from their guesses or estimates of the realized loss probabilities in their respective sessions upon observing the offered premiums. In the PLAY-AON and SPEC-AON conditions, subjects were rewarded $\$ 20$ for every correct estimate and nothing otherwise. In the PLAY-LSR and PLAY-QSR conditions, each consumer subject was paid for his/her estimate in one randomly chosen round and the realized outcome of whether there was a breakdown that took place at the end of the session. Denote the subject's estimate in the chosen round as $\pi$, and the realized outcome in the same round by the dummy variable $\Delta$, where $\Delta=1$ indicates that there was a breakdown and $\Delta=0$ otherwise. Then the payment formulas for the subject's estimate in the two conditions are:

$$
\begin{aligned}
\text { Payment in PLAY-LSR } & =\$ 100 \times[1-(\Delta-\pi)], \text { that is: } \\
& =\left\{\begin{array}{cc}
\$ 100 \pi & \text { if there is a breakdown; } \\
\$(100-100 \pi) & \text { if there is no breakdown; }
\end{array}\right.
\end{aligned}
$$

Payment in PLAY-QSR $=\$ 100 \times\left[1-(\Delta-\pi)^{2}\right]$, that is: 


$$
=\left\{\begin{array}{cc}
\$\left(200 \pi-100 \pi^{2}\right) & \text { if there is a breakdown; } \\
\$\left(100-100 \pi^{2}\right) & \text { if there is no breakdown. }
\end{array}\right.
$$

Hence the subject was incentivized in every belief reporting task by a penalty for the deviation of his/her guess from the realized outcome. The penalty was linear in the PLAY-LSR condition and quadratic in the PLAY-QSR condition. This can be contrasted with the AON conditions, in which the corresponding payment was based on the realized loss probability.

Given that our hypothesis and testable implications are phrased in terms of the expected value of the consumer's belief over the loss probability, a rigorous elicitation method should be one that elicits such an expected value. Theoretically speaking, of the elicitation methods discussed, only QSR might fulfill this aim, but only when the subject was risk neutral with respect to the probability guessing task. QSR is indeed widely used (cf. Nyarko and Schotter 2002; Andersen et al. 2014). However, any choice of elicitation method must attend to rigorous incentive compatibility as well as ease of understanding by the subject. While QSR fares better than other methods in terms of rigor, $\mathrm{AON}$ is the easiest to understand; as a result, Dufwenberg et al. (2011, footnote 15) used AON to measure a proxy for the expected values of subjects' beliefs. In addition, under AON, there is a very sharp difference in payment between correct and incorrect guesses (as befits the terminology "all-or-nothing"), which could make subjects more involved in the belief elicitation task than in other methods. Considering these tradeoffs, and the fact that measuring consumer beliefs is crucial to our study, we used multiple elicitation methods in order to enhance the robustness of our findings. For further discussion on these payment schemes as reasonable means to elicit subjective probability estimations, as well as previous studies that employ them, see Andersen et al. (2014)'s comprehensive overview.

- Insert Tables 1 and 2 and Fig. 2 around here -

\subsection{Results}


4.2.1 Preliminary observations. Fig. 2 is a graphical representation of the observations in the experiment. Table 1 lists the corresponding major statistics for every observed offer in the experiment. Table 2 summarizes consumer subjects' responses to offers in every condition. The premiums in the figure, tables, and our data analysis have all been normalized with respect to the compensation of $\$ 100$, in accordance with our model formulation.

A preliminary view of Fig. 2 suggests systematic violations the BREH (observations that lie above the dashed lines in the panels) over the whole range of observed offered premiums. Moreover, in the PLAY conditions, purchases (solid dots) seem to be at least as frequent, or even more so, than non-purchases (hollow dots) among observations that violate the BREH, in line with Testable Implication 1. The (proportional) frequency of violations also clearly decreases with the premium, in line with Testable Implications 2 and 2a. Lastly, note that the premium level(s) with highest demand in each PLAY condition, indicated by arrows in the panels, are invariably in the interior of the range of offered premiums, suggesting a non-monotonic relationship between demand and premium in line with Testable Implication 3.

In the following subsections, we shall report statistical tests in support of these preliminary observations. Before proceeding, we note that the order (round) in which an offer was presented did not have a notable effect on the responding subjects' behavior either. In all conditions, there is no significant correlation (at significance criterion $p<0.05$ ) between round and the average difference between guess and premium (column 5 in Table 1). Also, in every condition except SPEC-AON, there is no significant correlation between round and number of acceptances (last column of Table 1), and linear regression of number of acceptances on average guess, premium, and round did not yield a significant coefficient, again at significance criterion $p<0.05$. Henceforth we focus on reporting analysis of data without distinction between round numbers. 


\subsubsection{Tests of the BREH: Did consumer subjects' guesses satisfy basic requirements for}

rational expectations? On average (Table 2, last row), $20.8 \%$ of subjects' guesses violated the BREH. Given that a violation occurred, on average the guess was 0.051 higher than the premium; the corresponding median was at the comparable magnitude of 0.04 . These figures are indeed considerable, as indicated by the fact that they are about $20 \%$ of the prior mean of 0.25 . Also indicated in Table 1 is that the guesses were not significantly different from the premium with all except two offers according to $t$-test; the two exceptions, in Conditions PLAY-LSR and PLAY-QSR, have the premium being marginally less than the guesses, in violation of the BREH. Overall, these results suggest that the subjects' guesses were marginally not in violation of the BREH in most cases. An analysis at the level of individual subjects also shows that, in 71 out of 126 subjects across conditions, guesses were positively correlated with the offered premium at significance criterion $p<0.1$; only four subjects exhibited significantly negative correlations. Thus subjects seemed to partly base their guesses on the offered premium, though at the same time they often violated the BREH.

Lastly, the belief elicitation methods as well as play vs spectator manipulations in the different conditions did not create significant differences in behavior (even though, for example, the guesses in the SPEC-AON conditions seem to be directionally lower than those in the PLAYAON condition on average). For example, the proportion of violation is not significantly different from one condition to another: a $4 \times 1$ ANOVA of the individual violation percentages across the four conditions does not reveal any significant effect $(p>0.25)$. To illustrate our point further, we estimate a linear regression model using all the data in the experiment with subjects' guesses as the dependent variable and the offered premium, three condition dummies, and three condition $\times$ premium interaction terms as independent variables, while variances are clustered by 
subjects. The estimation yields a coefficient of 0.56 for the premium (standard error $=0.12$ ) at significance level $p<0.01$, but the estimated coefficients for all condition-related independent variables are non-significantly different from zero with $p>0.2$. Thus our conclusions from the experiment are robust across conditions.

\subsubsection{Tests of Testable Implication 1: What was the relationship between violation of the}

BREH and insurance purchase? For each offer in each condition, we count how many consumer subjects violated the BREH and purchased the offer, and then divide the count by the total number of consumer subjects who violated the BREH with that offer, to obtain an acceptance rate. The average of these acceptance rates is $56.7 \%$ in Condition PLAY-AON, $53.8 \%$ in Condition PLAY-LSR, and 51.4\% in Condition PLAY-QSR, all of which are higher than 50\% in accordance with Testable Implication 1.

To further test Testable Implication 1 on our data and to examine how violation of the BREH might affect purchase likelihood, we estimate the following logistic regression model pooling purchase decision and belief data from the three PLAY conditions:

$$
\text { Logit (Probability of purchase })=A+B \cdot d_{\mathrm{BREH}}
$$

where the dummy variable $d_{\mathrm{BREH}}=0$ if the subject violated the BREH and $d_{\mathrm{BREH}}=1$ if the subject followed the BREH. Variances are clustered by subjects in the estimation. The results are (standard error in parentheses): $A=0.41(0.14)$ and $B=-0.84(0.18)$. Both estimates are significantly different from zero at $p<0.01$. Consistent with Testable Implication 1 , violation of the BREH overall led to a higher than $50 \%$ purchase likelihood, as the estimate of $A$ is significantly positive. It also appears that violation of the BREH led to a higher purchase likelihood than otherwise, as the estimate of $B$ is significantly negative; this observation is consistent with the probabilistic choice framework behind our derivation of Testable Implication 
4.2.4 Tests of Testable Implications 2 and $2 a$ : Did violations of the BREH decrease with the premium? Table 1 shows clearly that, in agreement with Testable Implication $2 \mathrm{a}$, the number of violations of the BREH in every condition was always higher when the premium was less than the prior mean 0.25 than when the premium was higher than the prior mean. In addition, consistent with Testable Implication 2, there was a general decreasing trend in the frequency of violations as the offered premium increased; in fact, in every condition, the frequency of violations of the BREH was negatively correlated with the offered premium (correlation for Condition PLAY-AON: -0.836; Condition SEPC-AON: -0.936; Condition PLAY-LSR:-0.878; Condition PLAY-QSR: -0.855, all at significance level $p<0.01)$. Analysis at the level of individual subjects reveals a similar pattern. For each subject, we calculate the proportion of violations among premiums that were less than 0.25 as well as the corresponding proportion among premiums that were higher than 0.25 , and note down the difference as a dependent variable. We find that this difference, with mean 0.249 (s.d. $=0.305)$, is significantly larger than zero by $t$-test across all subjects $(p<0.001)$. We therefore conclude that our experiment provides evidence that is consistent with Testable Implications 2 and $2 \mathrm{a}$.

\subsubsection{Tests of Testable Implication 3: Was demand non-monotonic in the premium?}

Testable Implication 3 is also supported by the data. As can be seen in Table 1, the number of acceptances always peaked at some intermediate premium levels (highlighted in grey) in every one of the conditions PLAY-AON, PLAY-LSR, and PLAY-QSR; that is, the demand increased with the offer premium initially and then decreased with the premium. In fact, while all consumer subjects purchased at least one offer, 53\% (i.e., 16 subjects) in PLAY-AON did not purchase the offer with the lowest premium; the corresponding percentages for PLAY-LSR and 
PLAY-QSR are 48\% (16 subjects) and 35\% (11 subjects), respectively.

To further test Testable Implication 3 for our data, we estimate the following logistic regression model pooling purchase decision data from the three PLAY conditions:

$$
\text { Logit }(\text { Probability of purchase })=a+b_{1} \cdot \text { premium }+b_{2} \cdot(\text { premium })^{2} \text {. }
$$

Variances are clustered by subjects in the estimation. The results are (standard error in parentheses): $a=-0.37(0.34), b_{1}=6.14$ (2.89), and $b_{2}=-18.56$ (5.33). The estimates for $b_{1}$ and $b_{2}$ are significantly different from zero at $p<0.05$ and $p<0.01$, respectively, while that for $a$ is non-significantly different from zero $(p>0.2)$. We therefore conclude that our data provide evidence in support of an inverted-U dependence of demand for insurance on the offered premium, which is consistent with Testable Implication 3.

\section{- Insert Table 3 around here -}

4.2.6 Calibration of the belief formation process. We carry out a calibration of the belief formation process in our model, in particular to obtain empirical estimations of $\alpha$. To proceed, we need to specify the form of $f(p)$. We first adapt Einhorn and Hogarth (1985)'s specification for the adjustment function in their probabilistic inference model, which in our notation is $f(p)=-\theta$ (1-p-p $p^{\beta}$, where $\beta$ and $\theta$ satisfy $0 \leq \theta \leq 1$ and $\beta \geq 0$. But since our model theoretically requires that $1 \geq p-f(p) \geq 0$ and $f(p) \geq 0$ over $p \in[0,1]$ in accordance with the BREH, we must ensure that $f(0)=0$, so that we can impose an additional constraint of $\beta=0$. This reduces the function to the linear relationship $f(p)=\theta p$. Thus we estimate the following linear regression model pooling belief data from all four conditions:

$$
E_{C}[q \mid p]=\alpha \bar{q}+(1-\alpha)(p-\theta p)
$$

where the prior mean is $\bar{q}=0.25$ in our setup, and $\alpha$ and $\theta$ are the parameters to be estimated under the constraint $0 \leq \alpha \leq 1$ and $0 \leq \theta \leq 1$. Both parameters capture substantive characteristics 
of the consumer's belief formation. Recall that, according to our model, $\alpha$ indicates the relative weight (vis-à-vis the premium) of prior knowledge on the consumer's estimate of $q$.

Alternatively, the estimate of $\alpha$ can be interpreted as the extent to which the consumer neglected the premium when forming his/her beliefs. The estimate of $\epsilon$ would be a measure of, overall, how much the consumers' updated expected value of $q$ would be discounted (i.e., proportionally adjusted downwards) from $p$ in the premium-dependent component of their belief. Intuitively, 6 could also be interpreted as the consumers' overall rational expectations estimate of the insurer's target profit margin. This is because $\theta p c=f(p) \cdot c=p c-E_{C}^{R}(q \mid p) \cdot c$, where $E_{C}^{R}(q \mid p)$ represents the rational expectations component of the consumer's belief as discussed before. This implies that $\theta=\left[p c-E_{C}^{R}(q \mid p) \cdot c\right] / p c$, and thus 6 is the consumer's rational expectations estimation of the insurer's target profit margin. In fact, insurers have been commonly known to determine the premium of a package in terms of a target profit margin (called loading factor, see e.g., Kunreuther et al. 2013, p.47) over the expected loss to be covered; so it may be expected that consumer subjects would use a similar approach to infer the risk from the premium.

We use a normally distributed random-effects model in our regression to account for subject heterogeneity. We carry out separate estimations for each of the experimental conditions as well as on the pooled data from all conditions. The results are summarized in Table 3. Across conditions the estimated parameters all lie in the range $0.2<\alpha<0.45$ and $0.15<\theta<0.5$. That is, the premium had overall sizeable impact on belief formation, and there was a considerable extent of downward adjustment from the premium in the belief formation process. We also observe that the estimated normally-distributed heterogeneity in parameters is generally quite small, with across-subject standard deviation at the order of 0.01 or less throughout all estimations.

As can be expected from the literature on belief elicitation, the method of elicitation had 
some impact on the belief formation process itself, so that there are variations of the numerical parameter estimates across the PLAY-AON, PLAY-LSR, and PLAY-QSR conditions; it also needs to be noted that, in these cases, consumer subjects in different conditions responded to different sets of premium levels. The estimates also differ according to whether the subjects could purchase the insurance (the PLAY conditions) or would only guess the loss probability as a third party (the SPEC-AON condition). But further statistical analysis using $t$-tests suggests that the estimated $\alpha \mathrm{s}$ are actually not significantly different across conditions $(p>0.1$ in all comparisons). Meanwhile the estimated $\theta$ in PLAY-AON is significantly less than that in the other three conditions $(p<0.01)$, among which the estimated $\theta$ s are not significantly different ( $p>0.1$ in all comparisons).

Hence we consider that the estimation results for the pooled data should be representative of subject behavior in our experiment. As listed in the bottom row of Table 3, these results are (standard error in parentheses): $\alpha=0.26(0.028)$ and $\theta=0.36(0.016)$ (consistently, a nonlinear regression estimation on the pooled data with the full Einhorn-Horgarth specification yields $\beta=$ 0.00 with s.e. $=0.00$, and the same values with the other two parameters). Thus overall, consumer subjects did take the premium into account to some extent when forming beliefs about the loss probability, as the premium had an overall $74 \%$ weight on the formation of their estimate, while the prior mean had a $26 \%$ weight. This is consistent with the fact that all of our Testable Implications are observed in our data.

4.2.7 Discussion. Our experiment offers substantial evidence that consumers often violate rational expectations in insurance decision making. Regardless of the belief elicitation procedure, and regardless of whether subjects were in the role of consumers deliberating whether to purchase the offer or spectators considering the insurer's actions, violations the BREH occurred 
consistently in $20.8 \%$ of subjects' guesses on average across conditions. There is evidence that subjects who violated the BREH were more likely to purchase the insurance than not (in accordance with Testable Implication 1), and that purchase likelihood was positively related to violations of the BREH.

We have also obtained support for Testable Implications 2 and 2a, as we observed an especially high frequency of the BREH at low premium levels. There is also support for Testable Implication 3, as demand was upward (downward) sloping at low (high) premium levels, leading to an inverted-U-shaped demand curve. These results are consistent with the behavioral assumptions behind our derivation of those implications in the previous section. Importantly, subjects in our experiment were evidently aware of using the premium to update their belief regarding the loss probability. Had the subjects predominantly relied on the prior mean to form their beliefs with negligible regard for the premium (which corresponds to $\alpha$ being close to zero in our model), we would not have observed support for Testable Implication 3, as well as the observation that subjects' guesses were largely positively correlated with the premium, and an estimation result of $\alpha=0.26$. But since $\alpha>0$, subjects still often violated the BREH.

4.2.8 Note on insurers'strategy. The objective of our experiment was not the insurer subjects' premium-setting strategy, and hence we collected observations of only three insurers across conditions. Here we offer a tentative discussion regarding those insurers' strategy. First of all, we note that the premiums exhibit the following regularities:

(a) The premium of every offer in Table 1 is strictly higher than the true loss probability, suggesting that the insurer subjects always sought to avoid exposing themselves to an expected loss; this is consistent with the assumption behind the BREH;

(b) The premium in general increased with the true loss probability. The two variables had 
an overall significantly positive correlation of 0.84 at significance level $p<0.001$;

Both regularities (a) and (b) are consistent with the belief formation process that we use to derive the testable implications. In addition:

(c) On average, the insurer set the premium to achieve a profit margin (i.e., $(p-q) / p)$ of 0.42 (s.d. $=0.22$ ) over the expected loss to be covered. This can be compared with our estimated value of 0.36 for the parameter $\theta$, which represents the consumer's rational expectations estimate of the insurer's target profit margin. Thus the data suggest that, where the consumers sought to follow rational expectations, their estimates of the insurers' target profit margins were overall approximately correct.

It might be suggested that the insurers could have offered higher premiums than they had done when the true loss probability was low, so as to mimic an insurer with higher true loss probability. This would have resulted in a larger number of offers at the optimal premium in the inverted-U-shaped demand curve, compared to what have been observed. Our explanation for the present observations is as follows: even if the insurers intuited the consumers' belief formation process, and considered strategically setting the premium in accordance with the belief formation process, they would hardly be able to fully understand the heterogeneity among consumers in terms of risk attitude and other individual characteristics. Under such uncertainty, the insurers might be averse to setting high premiums that might drive down demand among some segments of consumers - even though the expected profit per purchase would suffer as a result (cf. Kunreuther et al. 1993 for research on how uncertainty could affect insurer decisions).

\section{Conclusions and discussion}

Our empirical findings are consistent with our model of the premium as an informational cue in 
insurance decision making. The belief formation process in our model incorporates dual impact from prior knowledge and the premium (in its standardized form as a proportion of the compensation), the latter via an anchoring-and-adjustment process. The model potentially leads to violations of basic rational expectations reasoning and a non-monotonic relationship between demand and premium. Accordingly we obtain experimental evidence of consistent, significant presence of violations of the BREH: $20.8 \%$ of subjects' estimates in the experiment exhibited such violations. Violations of the BREH led to a consumer subject being more likely to purchase than not (Testable Implication 1) and that there was a positive relationship between violations and purchase likelihood. We also find that violations of the BREH were especially frequent at low premium levels (Testable Implications 2 and 2a); moreover, demand was upward (downward) sloping at low (high) premium levels (Testable Implication 3), leading to an inverted-U-shaped demand curve. Calibration of the data on our model suggests that the prior mean had a $26 \%$ overall impact on belief, while the premium in general had $74 \%$ impact.

It needs to be emphasized that violation of the BREH is a very basic violation of rational expectations. A consumer does not need to perform sophisticated Bayesian updating to follow the BREH. All that is required is the realization that the loss probability cannot be higher than the premium as a proportion of the compensation, if the insurer aims to break even or to earn an expected profit from the deal. This simple logic is valid regardless of the external environment (including competition) that is faced by the insurer. It also needs to be clarified that, in real-life insurance decision making, various psychological factors may lead to the consumer's prior for the loss probability being biased given the available information and before the premium is offered at all. Examples include biases due to framing or the use of availability heuristic (Lichtenstein et al. 1978), or a self-positivity bias (Raghubir and Menon 1998) that makes that 
belief more optimistic than available information would allow. These issues are related to how the consumer's prior mean for the loss probability may be formed; our study is silent on these issues, as we focus on exogenous risk factors on which the insurers have an informational advantage over consumers. Our findings rather suggest that, regardless of whether consumers have formed their prior beliefs with or without biases, they would often violate rational expectations in the sense of insufficient appreciation of the premium as information. These violations could then contribute to a bias towards an overestimation of the loss probability and an increased likelihood of purchase.

\subsection{Power analysis}

Our experiment involved four conditions each having 30 to 33 subjects. In the following post hoc power analyses, we examine whether such sample sizes could provide sufficient power for the detection of some of the major effects we were investigating. Specifically, we focus on the logistic regressions for Testable Implications 1 and 3, as well as the correlation analyses for Testable Implication 2.

5.1.1 Testable Implication 1. To test the relationship between violations of the BREH and insurance purchase, we conducted a simple logistic regression on our experimental data. In the corresponding power analysis, we target a significance level of 0.05 and power of 0.8 and assume a relatively high intraclass correlation of 0.9 . We find that, in order to obtain the current results, a sample of 37 subjects would be required. Since our experimental data analysis involved 94 subjects from the three PLAY conditions, we conclude that our sample size was sufficient for this test.

5.1.2 Testable Implication 2. We used correlation analyses to test the relationship between violations of the BREH and the level of the premium in our data. We conducted four correlation 
analyses, one for each of the four conditions. The weakest correlation we found was -0.836 ( $p<$ 0.01) in the PLAY-AON condition. The corresponding power analysis suggests that, to obtain such a degree of correlation at a significance level of 0.05 and power of 0.8 , we would need only nine subjects. Since each experimental condition had at least 30 subjects, we conclude that our sample sizes were sufficient for this set of tests.

5.1.3 Testable Implication 3. We conducted logistic regressions to test the nonlinear relationship between premium and insurance purchase decision on our data. The corresponding power analysis suggests that, to obtain the linear and quadratic effects we have found at a significance level of 0.05 and power of 0.8 , we would need 75 and 69 subjects, respectively. Since our experimental data analysis involved 94 subjects from the three PLAY conditions, we conclude that our sample size was sufficient for this test.

\subsection{Future research directions}

Our experimental results present evidence for the series of testable implications that we establish in the theoretical modelling section (Section 2). The experimental results are therefore consistent with the assumptions behind our derivations of the implications. Future research could involve more direct tests of these assumptions, such as the weighted average assumption behind the belief formation model; the assumption $f^{\prime}(p)>0$ behind the derivation of Testable Implications 2 and $2 \mathrm{a}$; and the condition that $(1-\alpha)\left[1-f^{\prime}(0)\right]>q_{C}{ }^{\prime}(0)$ with a sufficiently large proportion of consumers, which would lead to Testable Implication 3. Section 2 also involves more basic assumptions such as a probabilistic choice model and i.i.d. zero-mean, symmetrically distributed shocks in the belief formation process. These can be examined in more systematic fashion in future research.

Another possible direction is to explore scenarios with competing insurers. In the present 
study, both the theoretical model and the experiment involve monopolistic insurers by design, as a simple backdrop for our focus on consumer decisions. However, in the very different scenario of a perfectly competitive equilibrium, insurers may truthfully reveal their information to consumers by offering an actuarially fair premium, so that $p=q$. Some form of market power may be needed for the premium to reveal some but not all of the underlying loss probability to the consumer. This reasonable conjecture awaits further research to examine in depth.

An underlying general premise of the present study is that consumers form beliefs about loss probabilities that influence their insurance decisions. While this premise is often assumed in empirical studies (e.g., Chen et al. 2009), it may not be true in some real-life contexts. People may neglect probability considerations when facing uncertainty that involves highly emotive negative outcomes such as terrorist attack (see Sunstein and Zeckhauser 2010). Kunreuther et al. (2001) also found that subjects' willingness to pay for insurance was effectively insensitive to changes in loss probability over ranges of extremely low loss probabilities (the highest loss probability used in their stimuli was 1 in 650 or 0.0015$)$. However, in many instances of insurance, such as extended warranties for household appliances, a breakdown event is typically not the kind of highly emotive outcome studied in the probability neglect literature, and the loss probability is often not extremely low. For example, referencing Consumer Reports, Huysentruyt and Read (2010) noted that a washing machine would break down with a $12 \%$ probability during the second or third year after purchase. Although Huysentruyt and Read (2010) found evidence of probability neglect in their surveys on consumers' willingness to pay for the extended warranty of a washing machine, Hogarth and Kunreuther (1995), in experiments that presented specific warranty packages for household appliances to subjects, concluded from their data that "subjects are likely to see probability of breakdown as an important factor" (p.27) that influences 
their purchase intentions towards the packages. Thus we consider that the premise is sound in many real-life insurance decisions.

Nevertheless, it would be worthwhile for policy-making purpose to investigate to what extent and in what format insurers should be required to inform the consumers about the loss probability. Such investigation could make consumers more aware of the very need to consider loss probability when making insurance decisions, and, furthermore, to improve consumers' considerations of the loss probability in aid of their decisions. Our study suggests that consumers are especially prone to overestimate the loss probability when the premium is a small proportion of the compensation. More specific studies on these cases might prove particularly valuable.

Lastly, we have focused throughout this study on the roles of the premium as a cost and an information cue to consumers. However, there is a literature that examines the premium as a capital component to the insurance company as well (e.g., Sherris 2006). Given that capital protects future liabilities, the premium is valuable to the customer in terms of the solvency of the insurer. It would be interesting to investigate in future studies whether, and to what extent, this aspect of the premium has an impact on consumers' insurance decision making. 


\section{References}

Abdellaoui, M., Baillon, A., Placido, L., \& Wakker, P. P. (2011). The rich domain of uncertainty: Source functions and their experimental implementation. The American Economic Review, 101(2), 695-723.

Andersen, S., Fountain, J., Harrison, G. W., \& Rutström E. E. (2014). Estimating subjective probabilities. Journal of Risk and Uncertainty, 48, 207-229.

Ball, S. B., Bazerman, M. H., \& Carroll, J. S. (1991). An evaluation of learning in the bilateral winner's curse. Organizational Behavior and Human Decision Processes, 48(1), 1-22.

Barseghyan, L., Molinari, F., O’Donoghue, T., \& Teitelbaum, J. C. (2013). The nature of risk preferences: Evidence from insurance choices. The American Economic Review, 103(6), 2499-2529.

Chade, H., \& Schlee, E. (2012). Optimal insurance with adverse selection. Theoretical Economics, 7, 571-607.

Charness, G., \& Levin, D. (2009). The origin of the winner's curse: a laboratory study. American Economic Journal: Microeconomics, 1(1), 207-236.

Charness, G., \& Dufwenberg, M. (2006). Promises and partnership. Econometrica, 74(6), 15791601.

Chen, T., Kalra, A., \& Sun, B. (2009). Why do consumers buy extended service contracts? Journal of Consumer Research, 36(4), 611-623.

Cutler, D. M., \& Zeckhauser, R. (2004). Extending the theory to meet the practice of insurance. Brookings-Wharton Papers on Financial Services, 2004(1), 1-53.

Dufwenberg, M., Gächter, S., \& Hennig-Schmidt, H. (2011). The framing of games and the psychology of play. Games and Economic Behavior, 73(2), 459-478. 
Einhorn, H. J., \& Hogarth, R. M. (1985). Ambiguity and uncertainty in probabilistic inference. Psychological Review, 92(4), 433.

Epley, N. (2004). A tale of tuned decks? Anchoring as accessibility and anchoring as adjustment. In Koehler, D. J. \& N. Harvey (Eds.), The Blackwell Handbook of Judgment and Decision Making (pp. 240-256). Malden, MA: Blackwell Publishing.

Epley, N., \& Gilovich, T. (2010). Anchoring unbound. Journal of Consumer Psychology, 20(1), 20-24.

Eyster, E., \& Rabin, M. (2005). Cursed equilibrium. Econometrica, 73(5), 1623-1672.

Faro, D., \& Rottenstreich, Y. (2006). Affect, empathy, and regressive mispredictions of others' preferences under risk. Management Science, 52(4), 529-541.

Hendren, N. (2013). Private information and insurance rejections. Econometrica, 81, 1713-1762.

Ho, T. H., Lim, N., \& Camerer, C. F. (2006). Modeling the psychology of consumer and firm behavior with behavioral economics. Journal of Marketing Research, 43(3), 307-331.

Hogarth, R. M., \& Kunreuther, H. (1989). Risk, ambiguity, and insurance. Journal of Risk and Uncertainty, 2(1), 5-35.

Hogarth, R. M., \& Kunreuther, H. (1995). Decision making under ignorance: Arguing with yourself. Journal of Risk and Uncertainty, 10(1), 15-36.

Holt, C. A., \& Sherman, R. (1994). The loser's curse. The American Economic Review, 84(3), 642-652.

Hsee, C. K., \& Weber, E. U. (1997). A fundamental prediction error: Self-others discrepancies in risk preference. Journal of Experimental Psychology: General, 126(1), 45.

Huysentruyt, M., \& Read, D. (2010). How do people value extended warranties? Evidence from two field surveys. Journal of Risk and Uncertainty, 40(3), 197-218. 
Jindal, P. (2015). Risk preferences and demand drivers of extended warranties. Marketing Science, 34, 39-58.

Kagel, J. H., \& Levin, D. (1986). The winner's curse and public information in common value auctions. The American Economic Review, 76(5), 894-920.

Kahneman, D., \& Tversky, A. (1979). Prospect theory: An analysis of decision under risk. Econometrica, 47(2), 263-291.

Kilka, M., \& Weber, M. (2001). What determines the shape of the probability weighting function under uncertainty? Management Science, 47(12), 1712-1726.

Kőszegi, B., \& Rabin, M. (2006). A model of reference-dependent preferences. The Quarterly Journal of Economics, 1133-1165.

Kreps, D. M., \& Wilson, R. (1982). Sequential equilibria. Econometrica, 50(4), 863-894.

Koufopoulos, K., \& Kozhan, R. (2014). Welfare-improving ambiguity in insurance markets with asymmetric information. Journal of Economic Theory, 151, 551-560.

Kubovy, M., Rapoport, A., \& Tversky, A. (1971). Deterministic vs probabilistic strategies in detection. Attention, Perception \& Psychophysics, 9(5), 427-429.

Kunreuther, H., Hogarth, R., \& Meszaros, J. (1993). Insurer ambiguity and market failure. Journal of Risk and Uncertainty, 7, 71-87.

Kunreuther, H. C., Pauly, M. V., \& McMorrow, S. (2013). Insurance and Behavioral Economics: Improving Decisions in the Most Misunderstood Industry. New York, NY: Cambridge University Press.

Kunreuther, H., Novemsky, N., \& Kahneman, D. (2001). Making low probabilities useful. Journal of Risk and Uncertainty, 23(2), 103-120. 
Lichtenstein, S., Slovic, P., Fischhoff, B., Layman, M., \& Combs, B. (1978). Judged frequency of lethal events. Journal of Experimental Psychology: Human Learning and Memory, 4(6), 551.

Luce, D. R. (1959). Individual Choice Behavior: A Theoretical Analysis. New York, NY: John Wiley \& Sons.

McFadden, D. (1980). Econometric models for probabilistic choice among products. Journal of Business, 53(3), part 2, S13-S29.

Moore, E., \& Eckel, C. (2003). Measuring ambiguity aversion. Unpublished manuscript, Department of Economics, Virginia Tech.

Nyarko, Y., \& Schotter, A. (2002). An experimental study of belief learning using elicited beliefs. Econometrica, 70(3), 971-1005.

Offerman, T., Sonnemans, J., \& Schram, A. (1996). Value orientations, expectations and voluntary contributions in public goods. The Economic Journal, 106(437), 817-845.

Rabin, M., \& Thaler, R. H. (2001). Anomalies: risk aversion. The Journal of Economic Perspectives, 15(1), 219-232.

Raghubir, P., \& Menon, G. (1998). AIDS and me, never the twain shall meet: The effects of information accessibility on judgments of risk and advertising effectiveness. Journal of Consumer Research, 25(1), 52-63.

Rothschild, M., \& Stiglitz, J. (1976). Equilibrium in competitive insurance markets: An essay on the economics of imperfect information. Quarterly Journal of Economics, 90(4), 629-649.

Sherris, M. (2006). Solvency, capital allocation, and fair rate of return in insurance. Journal of Risk and Insurance, 73, 71-96. 
Stiglitz, J. (1977). Monopoly, non-linear pricing and imperfect information: The insurance market. Review of Economic Studies, 44, 407-430.

Sunstein, C. R., \& Zeckhauser, R. (2010). Dreadful possibilities, neglected probabilities. In E. Michel-Kerjan \& P. Slovic (Eds.), The Irrational Economist: Making Decisions in a Dangerous World (pp. 173-185). New York, NY: PublicAffairs.

Sydnor, J. (2010). (Over) insuring modest risks. American Economic Journal: Applied Economics, 2(4), 177-199.

Tversky, A., \& Fox, C. R. (1995). Weighing risk and uncertainty. Psychological Review, 102(2), 269.

Tversky, A., \& Kahneman, D. (1983). Extensional versus intuitive reasoning: The conjunction fallacy in probability judgment. Psychological Review, 90(4), 293.

Tversky, A., \& Wakker, P. (1995). Risk attitudes and decision weights. Econometrica, 63(6) $1255-1280$. 
Table 1 Offer-by-offer statistics in the experiment including the offered premium (normalized with respect to the compensation of $\$ 100$ ), the true loss probability, the round in which the offer was made, the mean guess of loss probability (s.d. in parentheses), the mean of (premium-guess), the number of violations of the BREH, and the number of consumers (i.e., subjects in the role of drivers) accepting the offer. The data rows are arranged in ascending order of the premium. The offer(s) with the highest demand (number of acceptances) is highlighted in gray, while the premiums in the rows above (below) the dotted lines are less than or equal to (larger than) the prior mean 0.25 . With all except two offers across all conditions, the mean of (premium-guess) is not significantly different from zero by $t$-test at significance criterion $p<0.1$. The two exceptions, indicated by an asterisk (*) in the corresponding entries in column 5 , have the premium being marginally significantly less than the guesses $(p<$ 0.1 ), i.e., in a direction that violates the BREH.

(a) The PLAY-AON condition ( $N=30$ consumer subjects per offer)

\begin{tabular}{|c|c|c|c|c|c|c|}
\hline $\begin{array}{l}\text { Premium } \\
\text { offered }\end{array}$ & $\begin{array}{c}\text { True loss } \\
\text { probability }\end{array}$ & Round & Guess & Premium-Guess & $\begin{array}{l}\text { No. of guesses with premium < guess } \\
\text { (i.e., in violation of the BREH) }\end{array}$ & $\begin{array}{c}\text { No. of consumers } \\
\text { accepting offer }\end{array}$ \\
\hline 0.12 & 0.06 & 6 & $0.15(0.11)$ & -0.030 & 11 & 14 \\
\hline 0.15 & 0.07 & 3 & $0.17(0.12)$ & -0.021 & 11 & 14 \\
\hline 0.18 & 0.11 & 4 & $0.17(0.079)$ & 0.0063 & 8 & 14 \\
\hline 0.25 & 0.15 & 5 & $0.23(0.08)$ & 0.022 & 8 & 24 \\
\hline 0.30 & 0.15 & 1 & $0.21(0.086)$ & 0.092 & 2 & 24 \\
\hline 0.30 & 0.02 & 2 & $0.24(0.11)$ & 0.056 & 7 & 8 \\
\hline 0.35 & 0.14 & 8 & $0.31(0.086)$ & 0.041 & 5 & 15 \\
\hline 0.35 & 0.24 & 10 & $0.27(0.090)$ & 0.083 & 2 & 22 \\
\hline 0.40 & 0.28 & 7 & $0.31(0.12)$ & 0.092 & 4 & 11 \\
\hline 0.44 & 0.34 & 9 & $0.32(0.15)$ & 0.12 & 4 & 6 \\
\hline
\end{tabular}


(b) The SPEC-AON condition ( $N=32$ subjects per offer)

\begin{tabular}{cccccc}
\hline $\begin{array}{c}\text { Premium } \\
\text { offered }\end{array}$ & $\begin{array}{c}\text { True loss } \\
\text { probability }\end{array}$ & Round & Guess & Premium-Guess & $\begin{array}{c}\text { No. of guesses with premium < guess } \\
\text { (i.e., in violation of the BREH) }\end{array}$ \\
\hline 0.12 & 0.06 & 6 & $0.11(0.048)$ & 0.0078 & 14 \\
0.15 & 0.07 & 3 & $0.13(0.049)$ & 0.022 & 9 \\
0.18 & 0.11 & 4 & $0.14(0.065)$ & 0.038 & 10 \\
0.25 & 0.15 & 5 & $0.18(0.081)$ & 0.072 & 6 \\
\hline 0.30 & 0.15 & 1 & $0.18(0.092)$ & 0.12 & 4 \\
0.30 & 0.02 & 2 & $0.18(0.10)$ & 0.12 & 3 \\
0.35 & 0.14 & 8 & $0.23(0.091)$ & 0.12 & 4 \\
0.35 & 0.24 & 10 & $0.23(0.097)$ & 0.12 & 1 \\
0.40 & 0.28 & 7 & $0.21(0.11)$ & 0.19 & 1 \\
0.44 & 0.34 & 9 & $0.25(0.13)$ & 0.19 & \\
\hline
\end{tabular}

(c) The PLAY-LSR condition ( $N=33$ consumer subjects per offer)

\begin{tabular}{|c|c|c|c|c|c|c|}
\hline $\begin{array}{c}\text { Premium } \\
\text { offered }\end{array}$ & $\begin{array}{c}\text { True loss } \\
\text { probability }\end{array}$ & Round & Guess & Premium-Guess & $\begin{array}{l}\text { No. of guesses with premium < guess } \\
\text { (i.e., in violation of the BREH) }\end{array}$ & $\begin{array}{l}\text { No. of consumers } \\
\text { accepting offer }\end{array}$ \\
\hline 0.08 & 0.04 & 5 & $0.092(0.041)$ & $-0.0124 *$ & 19 & 17 \\
\hline 0.10 & 0.06 & 9 & $0.096(0.049)$ & 0.0045 & 14 & 22 \\
\hline 0.13 & 0.01 & 3 & $0.12(0.060)$ & 0.0061 & 15 & 16 \\
\hline 0.17 & 0.12 & 8 & $0.14(0.057)$ & 0.0336 & 8 & 13 \\
\hline 0.24 & 0.16 & 2 & $0.16(0.071)$ & 0.0779 & 4 & 18 \\
\hline 0.24 & 0.1 & 10 & $0.15(0.074)$ & 0.0861 & 6 & 19 \\
\hline 0.26 & 0.2 & 4 & $0.18(0.062)$ & 0.0800 & 2 & 10 \\
\hline 0.29 & 0.25 & 1 & $0.17(0.091)$ & 0.1206 & 3 & 13 \\
\hline 0.41 & 0.35 & 7 & $0.24(0.12)$ & 0.1709 & 2 & 5 \\
\hline 0.48 & 0.25 & 6 & $0.28(0.13)$ & 0.2036 & 0 & 5 \\
\hline
\end{tabular}


(d) The PLAY-QSR condition ( $N=31$ consumer subjects per offer)

\begin{tabular}{|c|c|c|c|c|c|c|}
\hline $\begin{array}{l}\text { Premium } \\
\text { offered }\end{array}$ & $\begin{array}{c}\text { True loss } \\
\text { probability }\end{array}$ & Round & Guess & Premium-Guess & $\begin{array}{c}\text { No. of guesses with premium < guess } \\
\text { (i.e., in violation of the BREH) }\end{array}$ & $\begin{array}{l}\text { No. of consumers } \\
\text { accepting offer }\end{array}$ \\
\hline 0.08 & 0.02 & 10 & $0.094(0.044)$ & $-0.014^{*}$ & 17 & 20 \\
\hline 0.15 & 0.08 & 6 & $0.14(0.053)$ & 0.011 & 11 & 12 \\
\hline 0.17 & 0.12 & 5 & $0.15(0.050)$ & 0.020 & 10 & 12 \\
\hline 0.20 & 0.1 & 9 & $0.16(0.071)$ & 0.043 & 11 & 22 \\
\hline 0.22 & 0.18 & 4 & $0.17(0.074)$ & 0.048 & 9 & 15 \\
\hline 0.24 & 0.05 & 8 & $0.17(0.069)$ & 0.068 & 4 & 13 \\
\hline 0.27 & 0.22 & 1 & $0.18(0.069)$ & 0.092 & 3 & 14 \\
\hline 0.35 & 0.3 & 3 & $0.23(0.093)$ & 0.12 & 2 & 5 \\
\hline 0.41 & 0.2 & 7 & $0.22(0.12)$ & 0.19 & 3 & 6 \\
\hline 0.47 & 0.4 & 2 & $0.29(0.15)$ & 0.18 & 3 & 5 \\
\hline
\end{tabular}


Table 2 Aggregate statistics in the experiment with each consumer subject (each responding subject in the SPEC-AON condition) as a unit of observation. The column " $N$ " indicates the number of consumer subjects in the PLAY conditions and the number of subjects in the SPEC-AON condition. The statistics listed include the mean of (premium-guess) and the mean percentage of violations of the BREH, and the mean percentage of offers accepted (s.d. in parentheses).

\begin{tabular}{ccccc}
\hline Condition & $\boldsymbol{N}$ & Premium-Guess & $\begin{array}{c}\text { Percentage of guesses with premium }<\text { guess } \\
\text { (i.e., in violation of the BREH) }\end{array}$ & Percentage of offers accepted \\
\hline PLAY-AON & 30 & $0.046(0.045)$ & $20.67 \%(20.50 \%)$ & $50.67 \%(16.80 \%)$ \\
SPEC-AON & 32 & $0.10(0.028)$ & $16.88 \%(10.30 \%)$ & Not Applicable \\
PLAY-LSR & 33 & $0.077(0.030)$ & $22.12 \%(9.92 \%)$ & $41.82 \%(13.10 \%)$ \\
PLAY-QSR & 31 & $0.076(0.026)$ & $23.55 \%(12.79 \%)$ & $40.00 \%(12.65 \%)$ \\
\hline All (pooled) & $126 / 94^{*}$ & $0.075(0.038)$ & $20.79 \%(13.95 \%)$ & $44.04 \%(14.83 \%)$ \\
\hline
\end{tabular}

$* N=126$ except for percentage of offers accepted where $N=94$.

Table 3 Calibration results of the model in the different experimental conditions, including estimations of the parameters (standard error in parentheses) in the calibrated model, and log likelihood fit statistics. All parameter estimates are significantly different from zero at $p<0.01$.

\begin{tabular}{ccccc}
\hline Condition & $\boldsymbol{N}$ & $\boldsymbol{\alpha}$ & $\boldsymbol{\theta}$ & $\mathbf{- 2 \boldsymbol { l o g } \boldsymbol { L }}$ \\
\hline PLAY-AON & 30 & $0.32(0.073)$ & $0.18(0.039)$ & 504.2 \\
SPEC-AON & 32 & $0.43(0.054)$ & $0.45(0.033)$ & 628.3 \\
PLAY-LSR & 33 & $0.22(0.039)$ & $0.43(0.025)$ & 729.2 \\
PLAY-QSR & 31 & $0.41(0.046)$ & $0.34(0.030)$ & 628.4 \\
\hline All (pooled) & 126 & $0.26(0.028)$ & $0.36(0.016)$ & 2437 \\
\hline
\end{tabular}


Fig. 1 Illustrative example showing $q_{C}(p)$ (thick solid curve) and the prior mean $\bar{q}$ over the range of $0 \leq p \leq 1$. The Bernoulli utility used to generate $q_{C}(p)$ in the figure is $U_{C}(x)=1-e^{-0.015 x}$ with compensation $c=100$, while the value of $\bar{q}$ used is 0.25 , as in the experiment. The function $\alpha \bar{q}+(1-\alpha) p$ (with $\alpha=1 / 4$ in this example) is indicated by the dotted line. The example satisfies $(1-\alpha)>q_{C}{ }^{\prime}(0)$. Violation of the BREH occurs when $\mathrm{E}_{C}[q \mid p]$ is above the diagonal in the figure (indicated by the shaded area); purchase (acceptance of offer) occurs when $\mathrm{E}_{C}[q \mid p]$ is on or above the $q_{C}(p)$ curve.

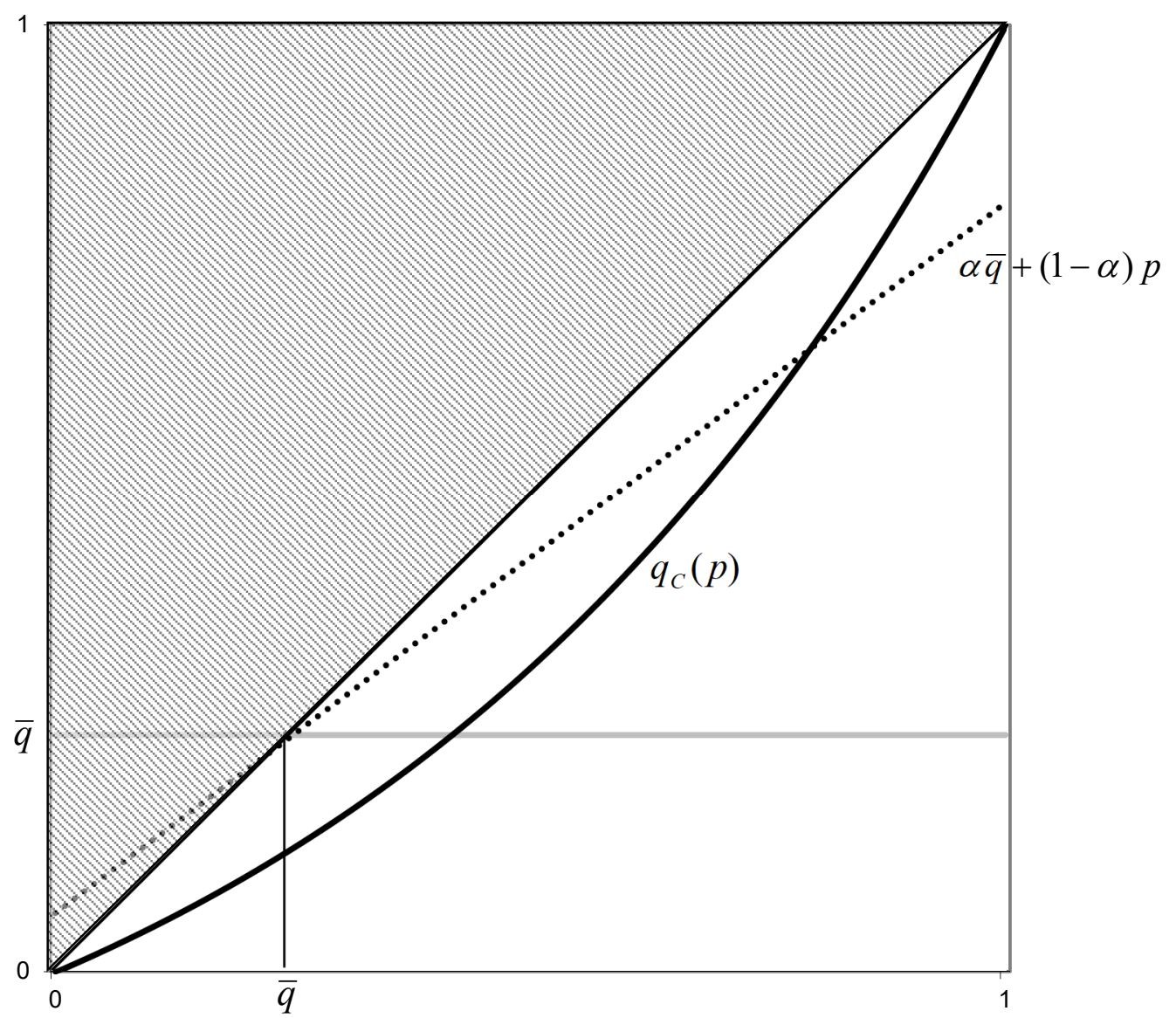

Premium $p$ 
Fig. 2 Subject guesses and purchase decisions in the experiment. Each dot (hollow or solid) represents one observation plotting the guess of a subject in a round versus the normalized premium offered. In the PLAY conditions, a solid (hollow) dot indicates that the subject accepted (did not accept) the offer in that observation, and arrow(s) indicate the premium level(s) at which the number of acceptances peaked within that condition (cf. Table 1). The solid line traces the average guess (without distinction between purchase decisions) at every offered premium level. The dashed straight line indicates where guess is equal to premium.
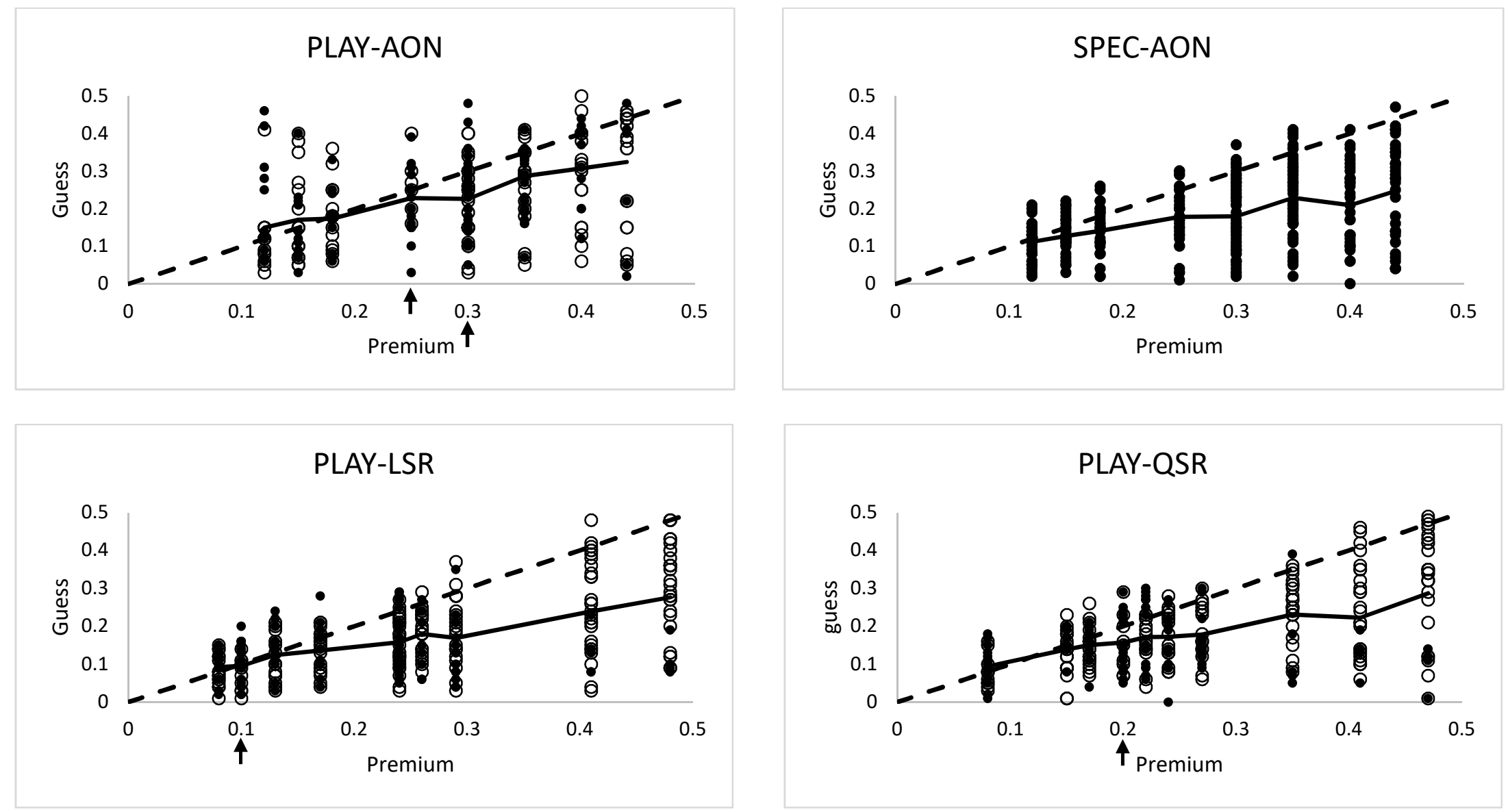


\section{Appendix A Equilibrium analysis of the insurance trading model}

In this appendix, we offer a game-theoretic analysis of the insurance trading model in the main text with an additional assumption that the Bernoulli utility functions of the two players (insurer and consumer) are common knowledge among them. We also allow for a general prior distribution for the loss probability $q$, which we label as $F(\cdot)$, in our analysis; in the experiment in this study, $F(\cdot)$ was specifically the prior uniform distribution over $0,0.01,0.02, \ldots 0.5$. Our objective is to formulate how, in equilibrium, an expected utility maximizing insurer would set the premium as a function of $q$, and how the consumer would form rational updated beliefs based on the premium. We focus on pure-strategy equilibria in which the insurer's offered premium is a single-valued function of the true loss probability $q$, and, upon observing an offered premium, the consumer accepts or rejects the offer with probability one. We also make the convenient tie breaking assumption that, if a consumer is indifferent between accepting and rejecting an offer, he/she will accept the offer.

In addition to the notations introduced in the main text, denote the insurer I's Bernoulli utility function as $U_{I}(\cdot)$. Without loss of generality and for reasons of expositional convenience, we adopt the normalization assumption that $U_{I}(0)=0$. Thus, if there is no trade, $I$ 's utility is $U_{I}(0)=0$. If there is a trade with premium $p$, I's expected utility from the trade is $q \cdot U_{I}(p c-c)+(1-q) \cdot U_{I}(p c) ; I$ should offer a contract with premium $p$ only if this quantity is not less than $U_{I}(0)$ i.e., only if:

$$
q \leq U_{I}(p c) /\left[U_{I}(p c)-U_{I}(p c-c)\right]=q_{I}(p),
$$

$q_{I}(p)$ being a function of $p$ (note that $U_{I}(p c-c)$ is negative because $p c-c<0$ and also because of our normalization assumption that $\left.U_{I}(0)=0\right)$. In the special case of a risk-neutral $I, q_{I}(p)=p$. We then introduce the following result:

Lemma A1 In equilibrium: (1) trade always occurs with the same premium, say ${ }^{*}$, regardless of $q$; (2) if there is trade, the consumer's updated belief of $q$ upon observing offered premium $p^{*}$ is the prior distribution truncated over $\left[0, q_{I}\left(p^{*}\right)\right]$. 
Proof. First note that $q_{C}(p)$ strictly increases with $p$ because $U_{C}(\cdot)$ is strictly increasing in its argument. Next note that, given $q$, the higher the premium the higher the expected utility of the insurer in the event of a trade. If an insurer with $q=q_{1}$ offers premium $p$ in equilibrium in (rational) expectation of a trade (which would be realized in equilibrium), it must be because: (a) inequality (1) in the main text is satisfied at with $q=q_{1}$, and (b) any higher $p$ would lead to no trade because the consumer would reject the offer. Thus any insurer with $q<q_{1}$ also finds it optimal to offer premium $p$ in expectation of a trade, since inequality (1) would still be satisfied. This implies that trade always occurs at the same premium, say $p^{*}$, and must occur whenever inequality (1) is satisfied with premium $p^{*}$, i.e., whenever $q$ is less than or equal to $q_{I}\left(p^{*}\right)$; hence the lemma.

Lemma A1 captures the intuition that an insurer with a low loss probability would tend to mimic that of a higher loss probability as long as the consumer would accept the offer of the latter, because by pretending that the loss probability is higher than the true value, the insurer can potentially charge a higher premium than otherwise. This essentially leads to all insurers charging the same premium in the event of a trade, when the consumer could only infer that the true loss probability cannot be higher than some upper bound (i.e., $\left.q_{I}\left(p^{*}\right)\right)$ because of inequality (1a), but nothing more. In that case, the consumer's conditional expected value of $q$ must be the expected value of the truncated distribution in Lemma A1, which is $\int_{0}^{q_{I}\left(p^{*}\right)} q d F / F\left(q_{I}\left(p^{*}\right)\right)$

Given an equilibrium, the consumer would have a well-defined willingness to pay, which is the highest premium at which the consumer would accept the offer. An expected utility maximizing insurer would therefore like to charge this willingness-to-pay as the premium as long as it satisfies inequality (1a), which then would lead to a trade. Therefore, the equilibrium premium with trade must be the maximum possible premium that satisfies Lemma A1 and inequality (1). This leads to the following:

Proposition A1 If $p_{m}=\max _{p \in(\underline{q}, 1)}\left\{p: \int_{0}^{q_{I}(p)} q d F / F\left(q_{I}(p)\right)=q_{C}(p)\right\}$ exists, then, in any equilibrium, the 
insurer presents an offer with premium $p^{*}=p_{m}<1$ whenever $q \leq q_{I}\left(p_{m}\right)$, in which case the consumer accepts the offer. If $p_{m}$ does not exist or if $q>q_{I}\left(p_{m}\right)$, there is no trade in equilibrium.

Proof. Any candidate $p^{*}$ that satisfies Lemma A1 and inequality (1) must satisfy $\int_{0}^{q_{I}\left(p^{*}\right)} q d F / F\left(q_{I}\left(p^{*}\right)\right) \geq q_{C}\left(p^{*}\right)$. An expected utility maximizing insurer would choose to offer a premium $p$ that is as high as possible if trade can result. The maximal value of $p$ that satisfies $\int_{0}^{q_{I}(p)} q d F / F\left(q_{I}(p)\right) \geq q_{C}(p)$ must be attained at either the upper bound of $p$ 's domain, namely 1 , or at the value $p_{m}$ that solves $\int_{0}^{q_{I}\left(p_{m}\right)} q d F / F\left(q_{I}\left(p_{m}\right)\right)=q_{C}\left(p_{m}\right)$. However, when $p=1, q_{I}(p)=1$, so that $\int_{0}^{q_{I}(p)} q d F / F\left(q_{I}(p)\right)$ is simply the prior mean which must be less than $q_{C}(p)=1$, and thus the equilibrium trade premium $p^{*}$ must be $p_{m}$ (if $p_{m}$ exists at all), and is offered by the insurer whenever $q \leq q_{I}\left(p_{m}\right)$. If $p_{m}$ does not exist or $q>q_{I}\left(p_{m}\right)$, there is no premium that can satisfy Lemma A1 and inequalities (1) and (1a) which leads to trade, and so there cannot be any trade. Note that the proposition is silent on out-of-equilibrium beliefs, such as what will be consumer's belief had the insurer offered a premium $p$ below $p^{*}$ - something that should occur with zero probability in equilibrium. On this issue, any updating that is consistent with Proposition A1 is admissible, a reasonable possibility being that $q$ is always distributed according to the prior truncated over $\left[0, q_{I}(p)\right]$, whatever $p$ is.

Overall, Proposition A1 extends the intuition of Lemma A1 and highlights that the insurer would offer a premium that is the highest possible at which the consumer would (just) like to trade - at least as long as such a premium still incentivizes the insurer to trade. This should indeed lead to trade given the consumer's equilibrium updating process, and the consistency requirement implies that the equilibrium premium with trade must be $p_{m}$, if it exists. Hence, if $p_{m}$ exists, the equilibrium has separating properties 
with which trade occurs whenever $q \leq q_{I}\left(p_{m}\right)$.

Finally, we note that while all equilibria under our consideration share the common characteristic of Proposition A1, they may differ in how insurers would charge if $p_{m}$ does not exist or when $q>q_{I}\left(p_{m}\right)$. The only requirement in these cases is that the consumer would reject the offer in equilibrium. If $p_{m}$ does not exist, and the insurer assumes that the consumer always have some positive probability of accepting an offer (see footnote 1), the insurer will always present an offer in these cases with a premium $p$ that satisfies $q \leq q_{I}(p)-$ but which will be rejected by the consumer with probability one. That is, the equilibrium is a pooling one with no trade. If $p_{m}$ exists but $q>q_{I}\left(p_{m}\right)$, Lemma A1 implies that the premium must be higher than $p_{m}$ for consumer's updated belief as stated in the lemma to fulfill rational expectations. Again a premium $p$ that satisfies $q \leq q_{I}(p)$ would be appropriate. 


\section{Appendix B Sample instructions in the experiment}

[All currencies are in Hong Kong dollars (US\$1 $\approx$ HK\$7.8).]

\section{Instructions for the PLAY-AON condition}

Welcome to our experiment. You will receive $\$ 70$ for showing up, regardless of the results. In addition, 10 of you will be chosen to receive a $\$ 100$ endowment with some risk, i.e., the ones being selected may lose his/her endowment with some probability for the reason to be discussed below. You will make 10 similar decisions and we will call them 10 rounds.

\section{The Drivers}

Imagine you have a car. The car may suffer from some type of mechanical failure or breakdown and need to be repaired. You will choose between 1) taking a chance on the car breaking down and paying for a repair, which cost $\$ 100$, and 2) purchasing insurance to insure yourself against having to pay for a repair. However, you do not know the exact probability of the breakdown. You only know the probability ranges from $0-50 \%$. If you choose to purchase the insurance, you will pay the premium and keep the rest of your money. The risk is then transferred to the insurer.

\section{The Insurer}

At the beginning of the experiment, one of you will be chosen randomly as the insurer. We have to determine the exact percentage chance out of the $0-50 \%$ range. Each of the percentage chances of the car needing a repair in the range is equally likely. The insurer will draw from a box a chip of 51 chips to determine the exact percentage chance of the car needing repair. (There are 51 numbers in the range of $0-50 \%: 0,1,2,3, \ldots, 49,50$.) Let's suppose the insurer draw a 9 . Then the percentage chance of the car needing repair is $9 \%$.

\section{The Premium}

The probability will only be known to the insurer until the end of the experiment. After the insurer learns the percentage chance, he/she will set the price for the insurance (also known as the premium). Then the premium will be announced to all drivers.

\section{The Driver}

As a driver, you are asked to make two decisions. First, the insurance decision is whether or not you accept the insurer's offer and buy the insurance. Second, you are asked to guess the exact percentage chance drawn.

\section{Driver's Payoff}

After all of you have made all 10 insurance decisions, for each round, one of the drivers will be chosen randomly to receive another $\$ 100$ endowment. This driver will draw a chip from another box of 100 chips $(1-100)$ to determine whether or not the car needs a repair. If the number is higher than the percentage chance, the car is fine. If the number the driver draws is equal to or smaller than the percentage chance of the car needing a repair, then the car has a breakdown. Following the above example where the drawn percentage chance is 9 , if the driver draws a 10 or above, the car is fine. If the driver draws a 9 or smaller, the car breaks down. The cost of the repair is borne by either the driver or the insurer depending on the driver's insurance decisions as discussed above. The cost of the repair simply goes back to the experimenter's research fund.

\section{Insurer's Payoff}

Since there will be 10 rounds, the maximum possible exposure for the insurer can be as much as $\$ 100 \times$ $10=\$ 1,000$. Thus only two out of 10 rounds will be selected randomly to determine the insurer's payoff. 
The insurer will receive 1) $\$ 70$ for showing up, 2) an endowment of $\$ 200$ and 3) the profit or loss from the two random rounds. For the remaining eight rounds, the insurer's decisions are still effective but the counterparty becomes the experimenter, instead of the insurer.

\section{The Logistics}

1. After all of you finished reading these instructions, we will randomly draw one of you to be the insurer.

2. In the beginning of each round, the insurer will draw from a box a chip numbered $0-50$ to determine the exact percentage chance of failure. Thus the percentage chances of failure vary from round to round. The percentage chances are private information to the insurer. You will only know these numbers after all 10 rounds.

3. The insurer set the premium for the insurance.

4. The premium is announced.

5. Then you are asked to decide if you want to buy the insurance or not at the premium set by the insurer.

6. You are also asked to guess the percentage chance drawn by the insurer. You will get an extra $\$ 20$ for each correct guess. Since there are 10 rounds, you have 10 chances.*

7. Your decisions will be collected. Please remember to fill out your name and student ID.

8. Since we have 10 rounds, steps $2-7$ are repeated 10 times.

9. After we collect all your decisions, we will randomly draw one driver for each round. Since we have 10 rounds, 10 drivers will be randomly selected.

10. Each of the drivers will draw a number from 1 to 100 as described above to determine if his/her car needs a repair. These drivers' payoff will depend on 1) their insurance decisions, 2) the number drawn by the insurer representing the percentage chance of failure, and 3) the number drawn by themselves determining if their cars need repair or not.

11. The 10 percentage chances drawn by the insurer will be revealed to all of you. For all drivers (not limited to the 10 who are selected), if you guess correctly what the percentage chance the insurer drawn, for each correct guess an extra $\$ 20$ will be added to your payoffs. The table below is for you to record your guesses.

12. We will pay you one by one and the experiment is over.

Note:

- $\quad$ At the end of the experiment, we will pay you individually and privately.

- $\quad$ Do not communicate with any other participant during this experiment. Participants who do not abide by this rule will be excluded from the experiment and from all payments.

- If you have questions concerning the experiment please raise your hand and I will come to you. In order not to influence other participants' decisions, your questions will be addresses privately.

- $\quad$ Thank you again for your participation in our research.

\footnotetext{
* In the PLAY-LSR Condition, participants are told that their payoffs from their guesses are $\$ 100 \pi$ if there is a breakdown and $\$(100-100 \pi)$, if there is no breakdown. In the PLAY-QSR Condition, participants are told that their payoffs from their guesses are $\$\left(200 \pi-100 \pi^{2}\right)$ if there is a breakdown and $\$\left(100-100 \pi^{2}\right)$, if there is no breakdown. In both of these conditions, participants are also told that only one of their ten guesses is randomly selected for payment. Participants are also told that their expected probability-payoff is maximized if they report probabilities truthfully.
} 


\section{Instructions for the SPEC-AON condition}

Welcome to our experiment. There are two parts in this experiment and you are participating in the Part 2. Part 1 has already run previously. In this part, you will make 10 similar decisions and we will call them 10 rounds. The relationship between the outcomes of Part 1 and your decisions and payoffs will be described below.

\section{The Game in Part 1}

This game was repeated 10 times (rounds) and involved a number of players: one insurer and some drivers.

The Drivers. Each driver has a car. The car may suffer from some type of mechanical failure or breakdown and need to be repaired. He/she will choose between 1) taking a chance on the car breaking down and paying for a repair, which cost $\$ 100$, and 2) purchasing insurance to insure himself/herself against having to pay for a repair. However, he/she does not know the exact probability of the breakdown. $\mathrm{He} / \mathrm{she}$ only knows the probability ranges from $0-50 \%$. If he/she chooses to purchase the insurance, he/she will pay the premium and keep the rest of his/her money. The risk is then transferred to the insurer.

The Insurer. At the beginning of the experiment, one of the participants will be chosen randomly as the insurer. We have to determine the exact percentage chance out of the $0-50 \%$ range. Each of the percentage chances of the car needing a repair in the range is equally likely. The insurer will draw from a box a chip of 51 chips to determine the exact percentage chance of the car needing repair. (There are 51 numbers in the range of $0-50 \%: 0,1,2,3, \ldots, 49,50$.) Let's suppose the insurer draw a 9 . Then the percentage chance of the car needing repair is $9 \%$.

The Premium. The probability will only be known to the insurer until the end of the experiment. After the insurer learns the percentage chance, he/she will set the price for the insurance (also known as the premium). Then the premium will be announced to all drivers.

The Insurance Decision. Seeing the premium set by the insurer, the drivers are asked to make insurance decisions on whether or not to accept the insurer's offer and buy the insurance.

Driver's Payoff. After all of the drivers have made all 10 insurance decisions, for each round, one of the drivers will be chosen randomly to draw a chip from another box of 100 chips $(1-100)$ to determine whether or not the car needs a repair. If the number is higher than the percentage chance, the car is fine. If the number the driver draws is equal to or smaller than the percentage chance of the car needing a repair, then the car has a breakdown. Following the above example where the drawn percentage chance is 9 , if the driver draws a 10 or above, the car is fine. If the driver draws a 9 or smaller, the car breaks down. The cost of the repair is borne by either the driver or the insurer depending on the driver's insurance decisions as discussed above. The cost of the repair simply goes back to the experimenter's research fund.

Insurer's Payoff. The insurer will receive the profit or loss from the insurance contracts on top of his/her show up fee.

\section{Part 2}

Your Task. Observing the premium set by the insurer, you are asked to make 10 guesses on the percentage chances drawn by the insurer in each round.

\section{Your Payoff.}

You are asked to make your estimation of the probabilities about the percentage chance in each round. You are asked to report these probabilities in percentages. You will get an extra \$20 for each correct 
guess. Since there are 10 rounds, you have 10 chances. The 10 percentage chances drawn by the insurer will be revealed to all of you at the end of this experiment.

\section{The Logistics}

1. Part 1 has already run previously. The percentage chances and the premium set by the insurer in the 10 rounds were recorded.

2. After all of you finished reading these instructions, the 10 premium set by the insurer will be announced.

3. You are asked to guess the percentage chance $(0-50 \%)$ drawn by the insurer.

4. This sheet will be collected. Please remember to fill out your name below. The amount will be determined later.

5. The actual outcomes of whether a breakdown occurred or not will be revealed to all of you. Remember the breakdown was jointly determined by the percentage chances $(0-50 \%)$ drawn by the insurer and the drivers drawn from the 100 chips.

6. Your decisions will be collected. Your payoff will be calculated accordingly. You will be paid one by one and the experiment is over. 